\title{
About Grafting of Single-Walled Carbon Nanotubes on the Oligo-N-vinyl Carbazole and Copolymer Involving $\mathrm{N}$-vinylcarbazole and Hexylthiophene
}

\author{
K. Alimi, B. Zaidi and M. Chemek \\ Université de Monastir, Unité de recherche Matériaux Nouveaux et Dispositifs \\ Electroniques Organiques, Faculté des Sciences de Monastir
}

Tunisia

\section{Introduction}

In recent years the use of Single-Walled Carbon Nanotubes (SWNTs) at the macroscopic scale by embedding them into a polymer matrix as well as the transfer of their physical properties to a polymer have attracted considerable interest (Andrés \& Blau, 2008; Canestraro et al., 2006; Zheng et al., 2009). Due to their excellent structural, mechanical and electronic properties, SWNTs could significantly improve the mechanical and optoelectronic properties of the polymer (Chen et al., 2009; Popov, 2004; Ryabenko et al., 2004). Consequently, reinforcing polymer with SWNTs can form high-performance polymer composites or nanocomposites, which could be used in manufacturing electronic organic devices such as nano-electronic displays (Bondavall et al., 2009; Capek, 2009; Fantini et al., 2009; Meng et al, 2009; Saunders \& Turner, 2008), chemical sensors (Ahuja \& Kumar, 2009), biosensors (Tam et al. 2009; Tripisciano et al., 2009). However, SWNTs are hardly soluble in common solvents and poor compatible with the polymer. Thus the uniformity of the dispersion process is not optimized and the resulting nanocomposite is often inhomogeneous and has undesirable properties. Among the factors innhibing the dispersion process is the shearing cohesiveness between SWNTs, which is governed by van der Waals interactions (Byron et al., 2006; Schroder et al., 2003). Different procedures have been applied in order to obtain more dispersed SWNTs. These procedures are essentially based on the centrifugation (Cathcart et al., 2009), sonification (Park et al., 2002; Brown et al., 2005) and the choice of solvent (Lau et al., 2005; Ganter, et al., 2009). Therefore, the quality of resulting composite is directly bound to the amount of SWNTs and the choice of the reactionnal medium and method.

In parallel, it was shown that Poly(N-vinylcarbazole) (PVK) is an attractive polymer owing to its photoconductive properties (Caste et al., 2003; Tang et al., 2008) and it has be used in xerographic systems (Moisan et al., 1991). This non-conjugated polymer is currently used as a good hole transporting material in photovoltaic devices (Barlier et al., 2009) or as a luminescent polymer emitting in the blue part when prepared in nanoparticles (Yoon et al., 2008). Otherwise, it can be easily doped with various dopant species (Safoula et al., 1998), which seems to be a good candidate for SWNTs functionalization. In the other hand, PVK 
has been mixed with inorganic or organic compounds to achieve emitting layers for new promising optoelectronics devices strongly improving the luminescence efficiency (Yap et al., 2009; Qiu et al., 2001).

Furthermore, recent works have shown that the use of both electron donating materials (polyparaphenylene, poly(3-alkylthiophene), carbazole based polymers...) and electron acceptor materials (fullurenes, carbon nanotubes) in heterojunctions can yield highly efficient photovoltaic conversion (Zhu et al., 2009; Cai et al., 2009). Poly (3-alkylthiophene) presents an interesting family of conjugated polymer regarding its optical, transport and electronic properties (McCulloug, 1998; Akcecelrud et al., 2003; On Chan et al., 1998). Moreover, the most promising hetero-junction was obtained by mixing poly(3hexylthiophene) (P3HT) as a donor polymer with phenyl $\mathrm{C}_{61}$-butyric acid methyl ester (PCBM) as an acceptor compound and the obtained materials exhibit a conversion efficiency of $\sim 5 \%$ (Kawano et al., 2009). Otherwise, it has been demonstrated that grafting of PVK to the thiophene (Th) based polymers exhibits a better optoelectronic properties (Chemek et al., 2010) compared to PVK or thiophene alone. In this context, it seems to be of interest to marry the properties of PVK/Th based copolymer with those of SWNTs.

In this chapter, we present in a first part a study of the evolution of the structural and optical properties of composites based on oligo-N-Vinyl carbazole (scheme 1a) mixed with SWNTs (scheme 1b), as a function of the solvent nature and temperature annealing (Wu et al., 2002). Our aim is firstly to reach a better functionalization process, which is directly bound to the amount of SWNTs allowed to a specific percolation threshold. Secondly, we tray to describe the grafting process between carbon nanotubes and the OVK molecules for which we report theoretical studies based on Density Functional Theory (DFT). From this systematic study, some other effects, such the solvent nature and annealing treatment effects on the SWNTs dispersion process can be also envisaged.

The second part of this chapter is however aimed on the investigation of a dependant concentration study of a novel polymer/SWNTs blend. The used polymer (scheme 1c) is based on Poly(N-vinylcarbazole) (PVK) and Poly(3-hexylthiophene) (P3HeT) named PVK$3 \mathrm{HT}$, synthesized by chemical oxidative way, using $\mathrm{FeCl}_{3}$ as an oxidant. The chemical synthesis way is similar to that used for the synthesis of the graft copolymer based on

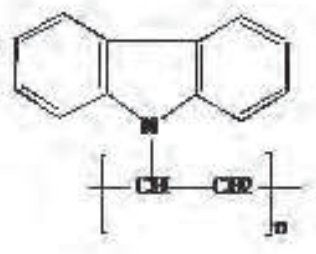

(a)

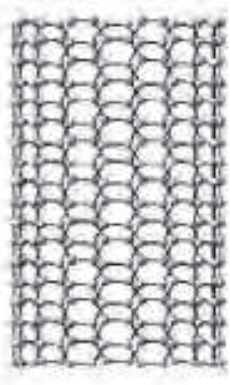

(b)
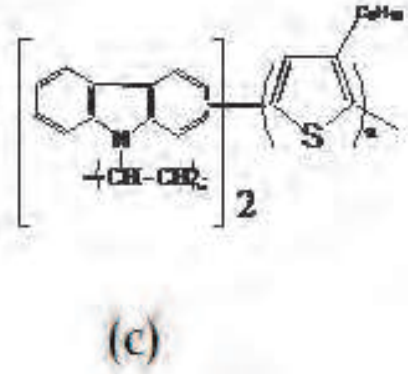

Scheme 1. Chemical structures of OVK (a), of the SWNTs (b) and of the PVK-3HT graft copolymer (c). 
Poly(N-vinylcarbazole) (PVK) and Poly(3-methylthiophene) (PMeT) named PVK-MeT (Chemek et al., 2010).

As our works is mainly focused on the relationship between the structure and the optoelectronic properties of the SWNTs/polymer, the obtained composites (oligo-N-Vinyl carbazole or copolymer involving Poly(N-Vinylcarbazole)-hexylthiophene mixed with SWNTs) have been studied by infrared absorption, Raman scattering, UV-visible absorption and photoluminescence spectroscopy.

\section{Functionalization of SWNTs with polymers}

SWNTs used to prepare the composite were purchased from Sigma-Aldrich. SWNTs were produced by electric arc technique, having a diameter between 1.2 and $1.5 \mathrm{~nm}$ and a length varying from 2 to $5 \mu \mathrm{m}$ as it is described elsewhere (Chapelle et al., 1998; Journet et al., 1999).

As the processing of SWNTs is generally blocked by their insolubility in most common solvents (Fantini et al., 2009), only the lower concentrations in weight can achieve a good dispersion process of carbon nanotube in the case of OVK polymer. In fact, the composite OVK/SWNTs have been obtained using either chloroform or chlorobenzene solvent at different SWNTs concentrations (Zaidi et al., 2010, Zaidi et al., 2011). In this chapitre, we give only resuts of the optimal concentration reashing a good functionalization process wihin intreactif character. In fact, it has been demonstrated that the maximum concentration reashing the above subject is $1.5 \%$ and $1.1 \%$ in SWNTs weight respectively when using chloroform and chlorobenzene solvents. These SWNTs weight concentrations are emphaziazed firstly by a homogenous SWNTs dispersion and secondly by a full dependant concentration study (Zaidi et al., 2011). When using (PVK- hexylthiophene), it is however found that we resahes $60 \%$ in the SWNTs weight, within a homogenous phase for which the obtained solution is progressively blacked with SWNTs contents. Therefore, it is of importance to give a dependant concentration study.

The composite obtention is based on the mixing procedure of SWNTs with the oligo-N-vinyl carbazole or with the polymer involving carbazole and hexyl-thiophene unit (figure 1), similarly to that described in some reports (Arab et al., 2005; Wu et al., 2002). All these composites are obtained by the use of either chloroform or chlorobenzene solvents. The polymers or the oligomer are firstly dissolved in the solvent. Then, a quantified ammount of already, dispersed SWNTs is added. In order to increase SWNTs weight concentration, the ammount of SWNTs are doubled from the one solution another $\left(\mathrm{C}_{\mathrm{i}}=2\left(\mathrm{C}_{\mathrm{i}-1}\right)\right)$. This functionnalization process consists of two major steps, the dispersion and the sonication process.

\subsection{Dispersion of SWNTs}

The dispersion process consists to isolate the bundled SWNTs in order to facilate the functionnalisation process for eventual reactionnal intraction. For that, some appropriate weights of SWNTs relative to the desired concentrations are manually crushed. Then, each amount is introduced in a recipient and maintained under energetic agitation (figure 1a) by the use of a classical finger, qualified by a different rotational velocity varying from 6000 to $24000 \mathrm{tr} / \mathrm{min}$, for the time of $75 \mathrm{~min}$. Our optimal velocity of the classical finger is in the range of 14000 to $18000 \mathrm{tr} / \mathrm{min}$. At this stage, constituing the dispersion process, the solution is progressively blacked and the corresponding volume shows a continious decreaese. 


\subsection{Sonication of the melange polymer/SWNTs}

For all desired SWNTs concentrations, the appropriate soluble fraction of either OVK or PVK -3HT must be alreaday prepared. After the dispersion process, the two components reperesenting the solution of both SWNTs or of the corresponding targets (OVK and PVK3HT) must be mixed as soon as possible in order to exploit the dispersed state of the SWNTs. This task leads to some solutions with different SWNTs weight fractions. For a better homogenity of the SWNTs in the polymer matrix, this mixing procedure is followed by a sonication process using an ultrasonically bath for $30 \mathrm{~min}$. The quality of the obtained homogenty can be preliminarly evidenced by the nature of the resulting solution. In fact, for lower SWNTs concentrations, generally we obtain a homogenous, visqous and light gray colored phase. However, highter SWNTs concentrations genrally show a bundled form, floating on the surface of the solution.

Experimental analyses can be made in solution or in thin film. In the case of OVK, composites (OVK and SWNTs) are deposited at room temperature with nearly uniform thickness on glass substrate for photoluminescence and Raman measurements. Silica and silicon were used respectively for optical absorption and infrared analysis. Before all hand, all substrates were cleaned in ultrasonically bath with deionized water and ethanol. In the case of PVK-3HT, as it is known, the processing in solution is easyer by referring to that in thin films state, all the measurement are done in solution using chloroform solvent. This choice is done to conserv the homogeniety of the SWNTs dispersion in order to carry out the effect of higher concentration in the lumminescent properties of the resulting composite.

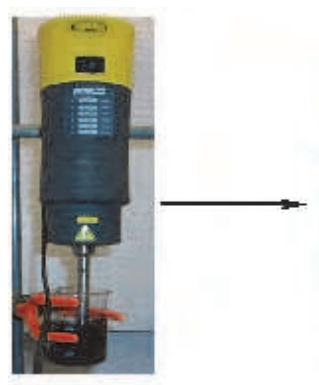

(a)

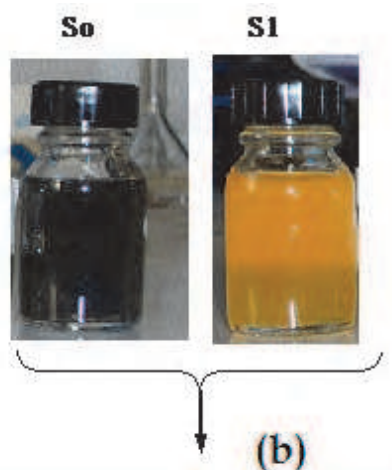

(b)

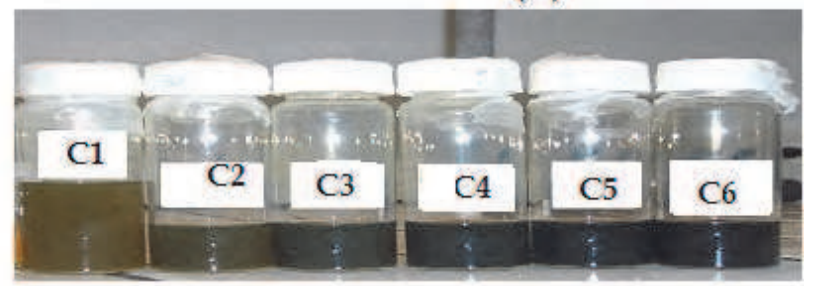

Fig. 1. Procedure used for the composite preparation: (a) SWNTs dispersion, S0: dispersed SWNTs, S1: solution of OVK or PVK-Het in the appropriate solvent and (b) the obtained polymer/SWNTs at different SWNTs weight concentrations. 


\section{Properties of SWNTs functionalized with short oligo-N-vinyl-carbazole}

Optical absorption, photoluminescence, infrared and Raman analyses were performed to argue the grafting of OVK on SWNTs in chloroform or chlorobenzene medium. Then, the effect of the nature of the solvent in the dispersion process and the eventual differences in the optical and vibrationnal properrties are carried out.

\subsection{Vibrational properties}

Figure 2, shows infrared spectra of OVK, and OVK/SWNTs composites at both chloroform and chlorobenzene solvent. Adding SWNTs leads to some changes in infrared vibrationnal features of the OVK. Peaks assignments are based on the previousely published results on the PVK or PVK/ SWNTs composites prepared by other procedure (Dobruchowska et al., 2008). However, the band intensitie variations relative to the present composite is recently described in our previous paper, aimed to the grafting reaction between OVK and SWNTs (Zaidi et al., 2010). In the case of chloroform, new bands appear at 1048, 1064, 1076, 1133, $1174,1297,1369,1718,1763$ and $2873 \mathrm{~cm}^{-1}$. As already reported in the literature (Baibarac et al. 2007), bands peaked at 1048, 1064, 1076, 1174 and 1718, $1763 \mathrm{~cm}^{-1}$ are the consequence of SWNTs insertion. The two peaks at 1133 and $2873 \mathrm{~cm}^{-1}$ are assigned to aliphatic $\mathrm{CH}_{2}$ in plane twist, and aliphatic $\mathrm{CH}_{2}$ stretching, respectively. However, the band at $1297 \mathrm{~cm}^{-1}$ are assigned to new C-C vibration, showing that SWNTs are successfully bonded with OVK. Moreover, some other bands centered at 418, 840, 1324, 1402, 1481, 1596, 1624 and $3047 \mathrm{~cm}^{-1}$ disappear in the case of OVK/SWNTs composite. These bands are respectively attributed to the following vibrations: ring breathing, aliphatic $\mathrm{C}-\mathrm{C}$ stretch, $\mathrm{C}-\mathrm{H}$ deformation of vinylidene groups, $\mathrm{CH}_{2}$ deformation of vinylidene groups, $\mathrm{CH}_{2}$ rocking, $\mathrm{CH}_{2}$ stretching, $\mathrm{C}$ $\mathrm{C}$ stretching of benzene groups and symmetric $\mathrm{CH}-\mathrm{CH}_{2}$ vibration. On the other hand, bands at 717 and $742 \mathrm{~cm}^{-1}$, associated to the deformation and rocking modes of $\mathrm{CH}$ groups respectively, are severely diminished.

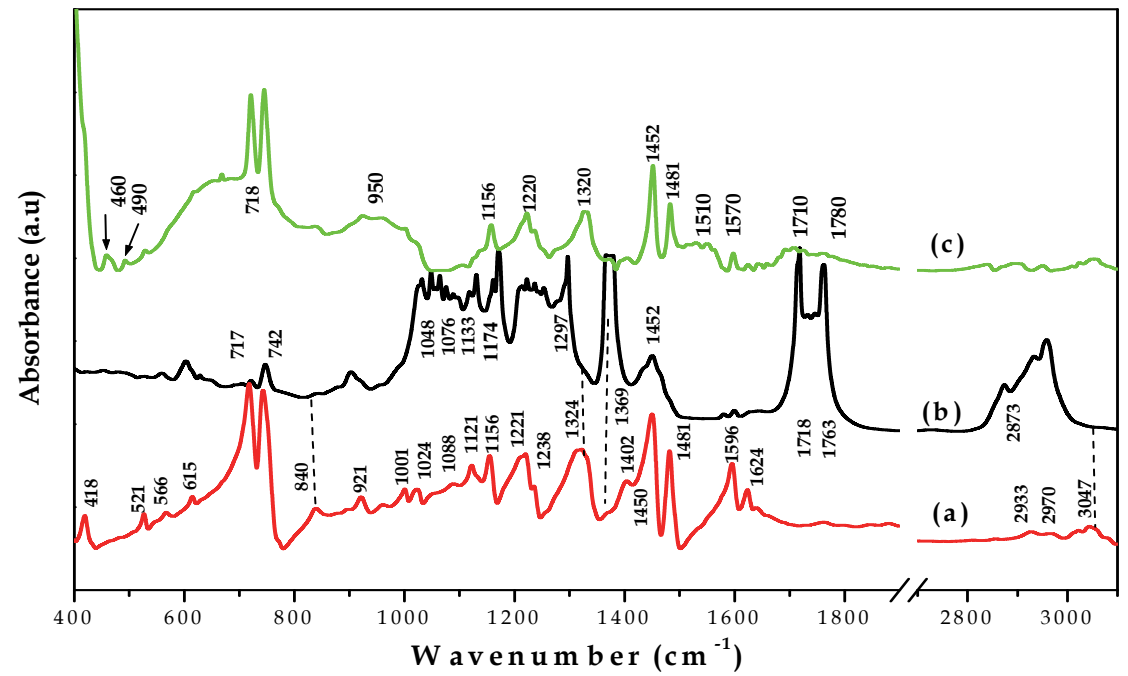

Fig. 2. Infrared spectra of: (a) OVK, and of OVK/SWNTs composite obtained using chloroform (b) and chlorobenzene (c) solvents. 
In the chlorobenzene solvent, the spectrum reveals clear differences by referring to that obtained with chloroform. The introduction of SWNTs leads to some modifications in the infrared band positions and intensities of OVK. In the spectral region varying from 1100 to 1650, bands located at 1156, 1220, 1320, 1452, 1481, 1596 and $1624 \mathrm{~cm}^{-1}$, attributed to the diffrent stretching modes of vinylidene groups (Bertoncello et al., 2006; Dobruchowska et al., 2008; Wu et al., 2007), are decreased. Furthermore, two additional features, ranging from 1510-1570 and 1680-1780 $\mathrm{cm}^{-1}$, constituting habitually the vibration mode characteristics of C-C relative to SWNTs appeared. We suggest therefore that the nanoscopic structure of vinylidene groups is affected by adding SWNTs, without covalent attachment of both components. As we show band which appears at the $1297 \mathrm{~cm}^{-1}$ in the case of chloroform solvent is not present. At the same time, bands relative to the SWNTs are very low in intensity, impliying that the functionnlaization process do not leads to a reactionnal effects. In figure 3, we present Raman spectra of OVK, SWNTs and OVK/SWNTs composites obtained at both medium (chlorobenzene or chloroform). For SWNTs and OVK/SWNTs composites spectra, the data are normalized to the main peak of the nanotube spectrum around $1590 \mathrm{~cm}^{-1}$ ( $\mathrm{G}$ band). Assignments of the full spectrum are strictly based on those of PVK, SWNTs and the composite PVK/SWNTs prepared by other procedure (Pei et al., 1999). The band intensity is however recently described (Zaidi et al., 2010, Zaidi et al., 2011).

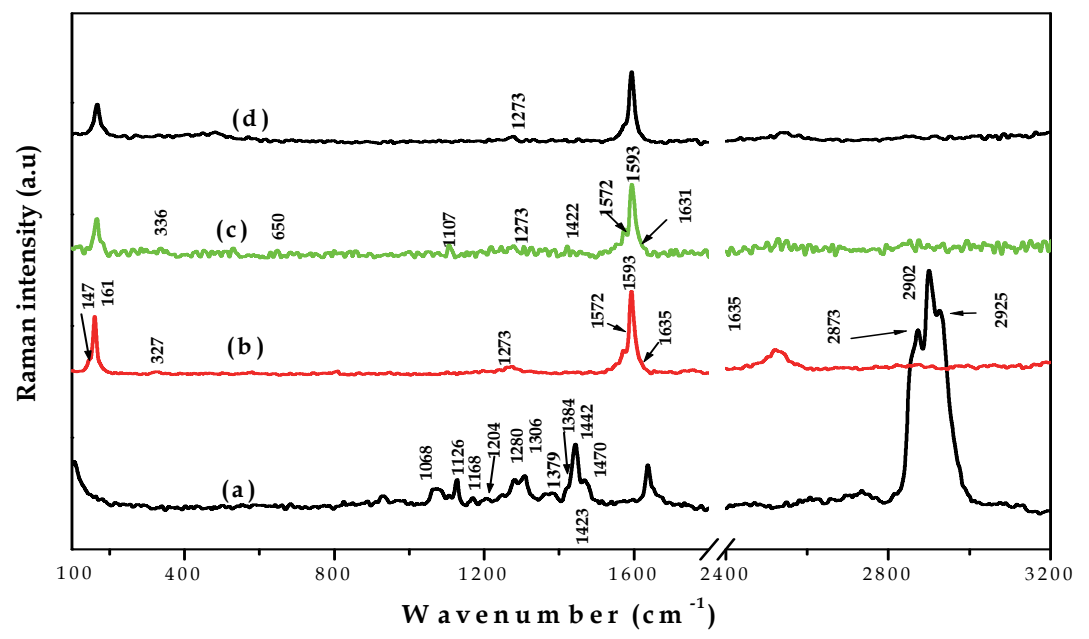

Fig. 3. Raman spectra of: (a) SWNTs, (b) OVK, and of OVK/SWNTs composite obtained using chloroform (c) and chlorobenzene (d) solvents.

In both chloroform or chlorobenzene mediums, significant changes are clearly shown by adding SWNTs on the OVK spectrum. First, we note that the most intense vibrations of OVK (1126, 1306, 1423, $\left.1635 \mathrm{~cm}^{-1}\right)$, and of SWNTs (161, 327, 1572, 1273 and $\left.1593 \mathrm{~cm}^{-1}\right)$ are found in the OVK/SWNTs composite spectrum. However, the Raman bands of SWNTs are clearly observed, but those of OVK have severely diminished, due to their lower intensity. Secondly, some bands with relatively higher intensity $(1168,1204,1379,1384,1442,1470$, 2873, 2902 and $2925 \mathrm{~cm}^{-1}$ ) in the case of OVK disappear. These bands are respectively ascribed to the following vibration modes: $\mathrm{C}-\mathrm{H}$ deformation in benzene rings, rocking of 
methylene in polyvinyl, ring vibration, quinoid $\mathrm{C}-\mathrm{C}$ stretching, $\mathrm{C}-\mathrm{H}$ in hetero-five member ring vibration, $\mathrm{C}-\mathrm{N}$ stretch, symmetric $\mathrm{CH}_{2}$ stretch, asymmetric $\mathrm{CH}_{2}$ stretch and $\mathrm{CH}-\mathrm{H}_{2}$ stretching.

Althought the composites spectra present a global shape similarity in full range frequencies, some interesting differences (figure 4) can be checked from both radial breathing and tangential modes (RBM and TM) when they are presented separately.

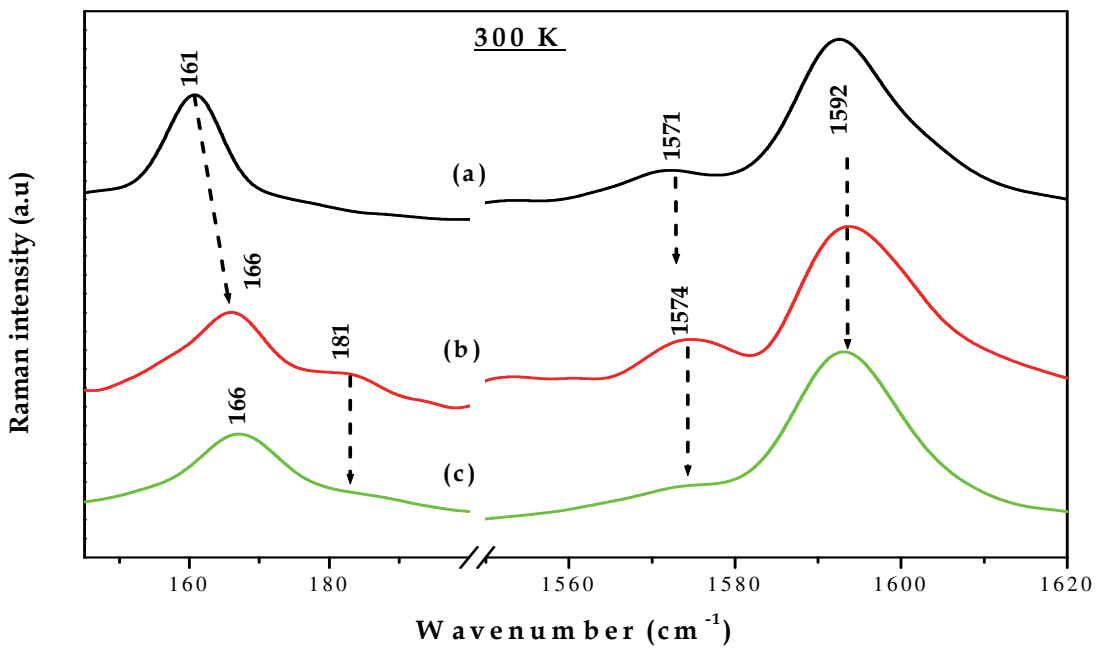

Fig. 4. Change on the rdaial breathing and tangentiel modes from SWNTs to the composite preapared using chloroform (b) and the chlorobenzene (c) solvents.

In fact, the band of SWNTs situated at $161 \mathrm{~cm}^{-1}$ is associated to the RBM of isolated SWNTs. The appearance of an intense peak at $181 \mathrm{~cm}^{-1}$ is attributed to the RBM of bundled SWNTs (Wang et al., 2004; Yang et al., 2006). The up-shift of $20 \mathrm{~cm}^{-1}$ is related to the tube-tube interaction (Rao et al., 2001) and could be considered also as signature of SWNTs' aggregates. The peak position $(v)$ of this band is related to the tube diameter $(d)$ through the relation: $v\left(\mathrm{~cm}^{-1}\right)=223.75 / \mathrm{d}(\mathrm{nm})$. This band indicates that, for SWNTs, the resonance occurs at the mean diameter of $1.38 \mathrm{~nm}$. Modifications from SWNTs to the resulting composites are firstly limited to the up-shifting of the band at $161 \mathrm{~cm}^{-1}$ towards $166 \mathrm{c} \mathrm{cm}^{-1}$. This shift can be related to the intercalation of the OVK oligomers into bundled SWNTs.

The band at $181 \mathrm{~cm}^{-1}$ is severely diminished by the use of chlorobenzene solvent. We conclude therefore that the intercalation of the OVK molecules is homogenous in the case of the composite obtained using chlorobenzene solvent for which SWNTs have a mean diameter of $1.34 \mathrm{~nm}$. This result supports potential role of the latter solvent in the dispersion process as the case of aromatic halogenated solvent (Ganter, et al., 2009).

These changes are related to the intercalation of the polymer into bundled SWNTs. For the TM (1500-1650 $\left.\mathrm{cm}^{-1}\right)$, by referring to that of SWNTs, except the narrowing effect, there is no significant changes, except the intensity decrease of the peak at $1571 \mathrm{~cm}^{-1}$ which illustrates a more change from 2D to 3D symmetry (Eklund et al., 1995).. In fact, all these changes observed either in the chloroform or chlorobenzene solvents can be related to the charge transfer complex formation (Bendiab et al., 2002; Claye et al., 2001; Wise et al., 2004). 


\subsection{Optical properties}

Optical absorption spectra of OVK and OVK/SWNTs composites preapared by using either chloroform or chlorobenzene solvent are shown in figure 5. All mesaurements are collected at room temperature.

The main absorption bands of OVK are peaked at 232, 260, 294, 330 and $343 \mathrm{~nm}$, as it is previously described in the case of PVK (Bertoncello et al., 2006). For the chloroform solvent and for wavelengths longer than $350 \mathrm{~nm}$, OVK is transparent. Then, by referring to the OVK spectrum, the two bands at 232 and $343 \mathrm{~nm}$ sudden a slight red shift to 237 and $352 \mathrm{~nm}$ respectively. This red shift can be attributed to the interaction between SWNTs and OVK as it is reported in the case of multiwalled carbon nanotubes (MWCNs) (Wu et al., 2007). It is interesting to note that in the spectral region varying from 400 to $2000 \mathrm{~nm}$ (Zaidi et al., 2010), the OVK/SWNTs composite's absorbance decreases gradually similarly to those of halogendoped PVK (Safoula et al., 1998). Similar effect has been also demonstrated in the case of SWNTs/Polyaniline obtained by an electro-synthesis process (Huang et al., 2003). This spectral region $(\lambda>400 \mathrm{~nm})$, presents three Lorentzian line-shapes of maximum absorbance centered at 450, 943 and $1246 \mathrm{~nm}$. These bands are situated at 720, 976 and $1823 \mathrm{~nm}$ in the SWNTs optical spectrum from which the last band $(1823 \mathrm{~nm})$ is the most intense and is attributed to the inter-band optical transition in the semi conducting SWNTs. Therefore, adding OVK to SWNTs leads to a blue shifting, showing that OVK is functionalized with SWNTs.

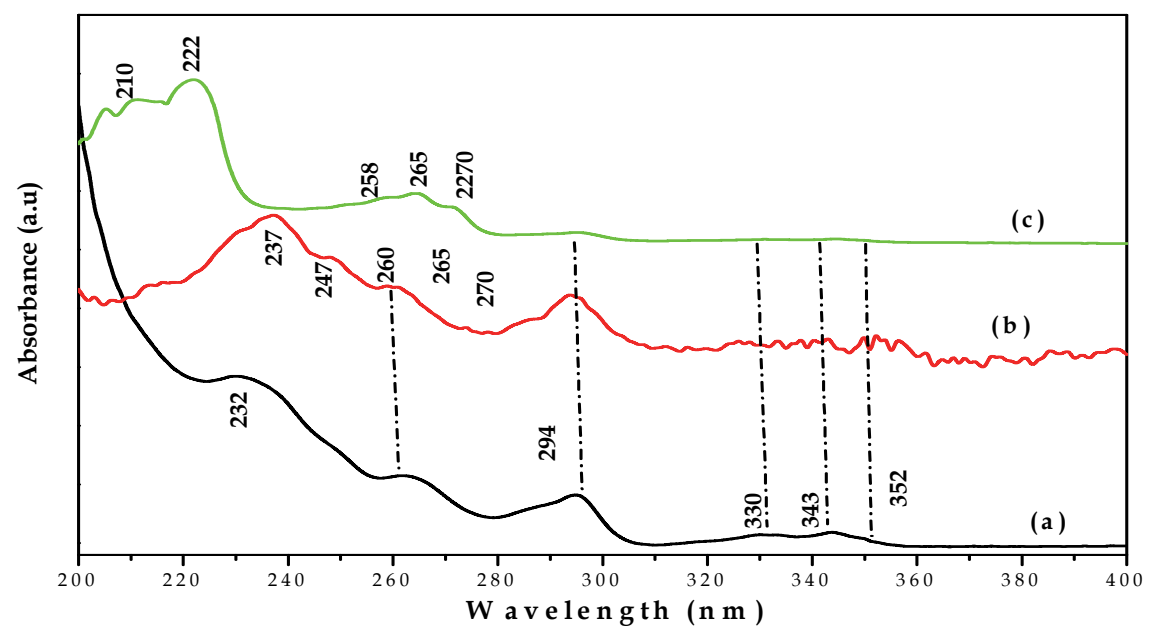

Fig. 5. Optical absorption spectra of OVK (a) and of OVK/SWNTs composites obtained either in chloroform (b) or in the chlorobenzene (c) solvents.

In the case of chlorobenzene and compared to the pristine OVK, (Bertoncello et al., 2006; Nam et al., 2002; Wu et al., 2007), new peaks appear around 210, 258, and $270 \mathrm{~nm}$ respectively, suggesting the formation of a charge transfer complex (Nam et al., 2002). Moreover, the three bands at 295, 331 and $344 \mathrm{~nm}$ are severely decreased, implying that SWNTs interacts with OVK (Wang et al., 2004; Wu et al., 2007). The main band in the blue side is blue-shifted, traducing the shorteness of the effective chain length of OVK (Yuna et al., 2008). 
Figure 6 shows photoluminescence (PL) spectra of OVK and OVK/SWNTs composites. First, we note that PL spectrum of OVK is characterized by a broad emission situated in the spectral range $350-550 \mathrm{~nm}$, which is constituted of three peaks. The pronounced peak located at $397 \mathrm{~nm}(3.12 \mathrm{eV})$ has been formerly assigned to lower-energy excimer, while the two lower intensity peaks are centered at $376(3.29 \mathrm{eV})$ and $428 \mathrm{~nm}(2.90 \mathrm{eV})$, as recently described in literature (Upadhyay et al., 2008). In comparison with OVK, dramatic reduction of PL intensity is observed for OVK/SWNTs. The strength of PL quenching effect due to the SWNTs addition is more illustrated by the ratio $\left(\Phi F / \Phi^{\prime} F\right)$ of photoluminescence intensities related to pristine OVK $(\Phi F)$ and OVK functionalized SWNTs $\left(\left(\Phi^{\prime} F\right)\right.$, equal to 1.3 and 1.2 for the composite obtained by the use of chloroform and chlorobenzene respectively. Also, by inserting SWNTs, a slight red shift of the emission band at $392 \mathrm{~nm}(3.16 \mathrm{eV})$ to $404 \mathrm{~nm}(3.06$ $\mathrm{eV}$ ) has been observed in both cases. This quenching effect is caused by the scattering due to nanotubes presence (Wu et al., 2002). It is also noted that an energy tranfer has been occured, as shown by the mutual change of both $\mathrm{Pl}$ components situated at lower wavelength.

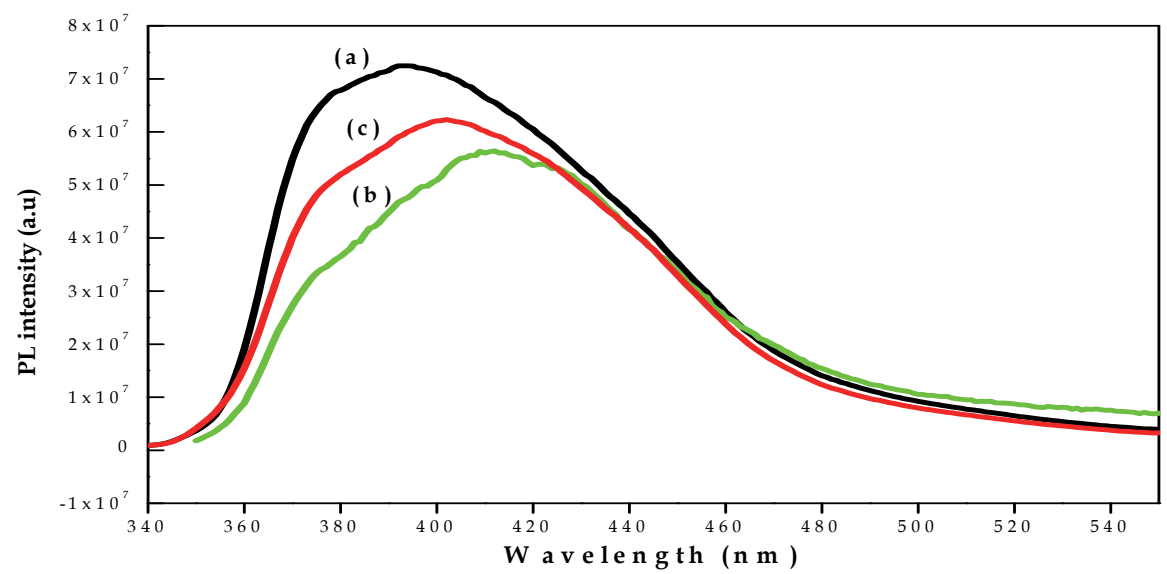

Fig. 6. PL spectra of OVK (a) and those of OVK/SWNTs composites obtained in chloroform (b) and in the chlorobenzene (c) solvents.

\subsection{Grafting mechanism}

From the above presented results, it appears that vibrationnal and optical properties of the resulting composite are derived from those of both OVK and SWNTs, as the case of PVK/SWNTs composites obtained by different experimental processes (Nam et al., 2002; Upadhyay et al., 2008; Wu et al., 2007). Thus, we can say that OVK is successfully functionalized with SWNTs but only in the case of chloroform solvent. In this context, infrared and Raman analysis show that the main perturbations induced in the chemical structure of OVK by adding SWNTs are limited to the vinylidene groups. Also a new C-C infrared band is created at $1297 \mathrm{~cm}^{-1}$.

All experimental results let to conclude that a covalent bonding of OVK takes place in the vinylidene groups as indicated in figure 7 . The obtained structure in the case of chloroform solvent is a grafting of OVK on the nanotube side wall. This hypothesis is also supported by the changes observed in infrared spectrum of OVK, especially by the disappearance of peaks 
at 1402, 1481, 1596, $3047 \mathrm{~cm}^{-1}$ characteristic of vinylidene groups and the apparition of two $\mathrm{C}-\mathrm{H}_{2}$ features at 1133 and $2873 \mathrm{~cm}^{-1}$. Similar grafting reaction has been proposed for PVK/MWCNs (Eklund et al., 1995) and for PVK/C60 (Wang et al., 2004) composites. It is now difficult to confirm that all $(\mathrm{n}=\mathrm{P})$ or a few number $(\mathrm{P}<\mathrm{n})$ of vinylidene groups are grafted to the SWNTs. Also, if it is the case of a partial reaction, the reactive or unreactive units can be arranged or not.

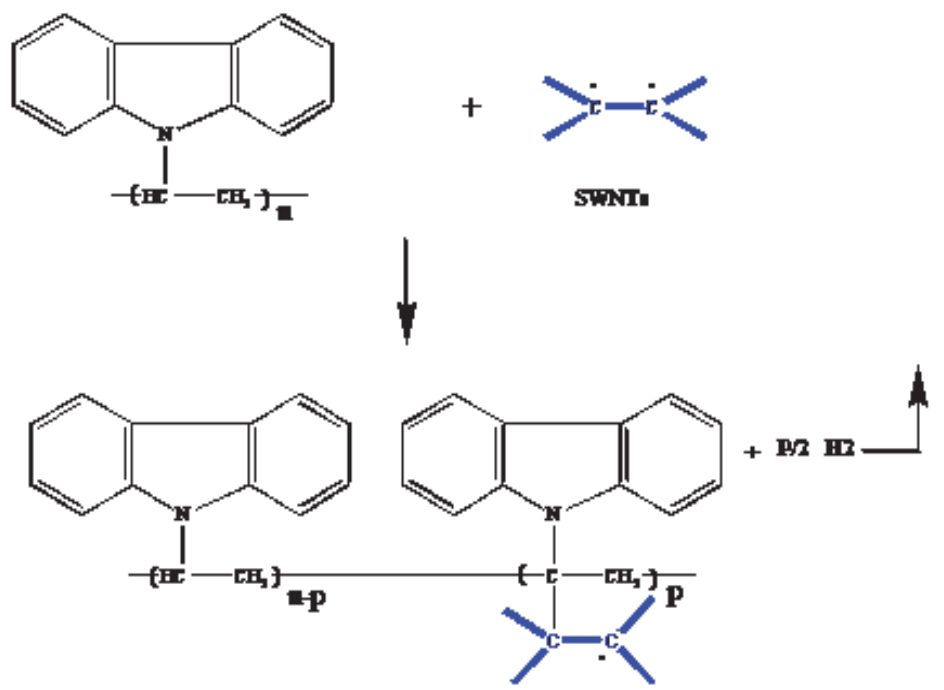

Fig. 7. Covalent bonding of OVK on the SWNTs side wall.

\section{Effect of annealing treatments}

The composite film obtained after solvent-evaporation is introduced in an oven and is subsequently heated under dynamic secondary vacuum $\left(10^{-7}\right.$ bar $)$ at the temperature of 333 $\mathrm{K}$ for about $1 \mathrm{~h}$ as it is previously described (Wu et al., 2002). The choice of this temperature is strictly based on the PVK thermal properties (Alimi et al., 1998).

\subsection{Vibrational properties}

For infrared analysis and after annealing at $333 \mathrm{~K}$ (figure 8), no changes are observed in the case of chloroform solvent. However, in the case of chlorobenzene, the shape of infrared spectrum is strongly affected. More resolved spectra for which new bands appear at 1133, $1174,1297,1369,1718,1763$ and $2873 \mathrm{~cm}^{-1}$. The obtained spectra are closed to that obtained with chloroform solvent. According to the literature (Wang et al., 2004), bands peaked at 1174, 1369, 1718 and $1763 \mathrm{~cm}^{-1}$ are the signature of SWNTs. The others (1133, 1297 and 2873 $\mathrm{cm}^{-1}$ ) are respectively assigned to aliphatic $\mathrm{CH}_{2}$ in plane twist, new C-C vibration and aliphatic $\mathrm{CH}_{2}$ stretching respectively. The new band at $1297 \mathrm{~cm}^{-1}$, shows that SWNTs are successfully bonded with OVK. Moreover, some others bands centred at 418, 840, 1324, $1402,1481,1596,1624,3047 \mathrm{~cm}^{-1}$, in the case of OVK already presented in figure 2, disappear in the case OVK/SWNTs composites. These bands are mainly attributed to the different stretching mode of vinylidene groups. We think therefore that for such SWNTs weight 
concentrations, a covalent attachment of OVK to the SWNTs takes place, via vinylidene groups as it is said before in the case of chloroform solvent in both annealed and not annealed states.

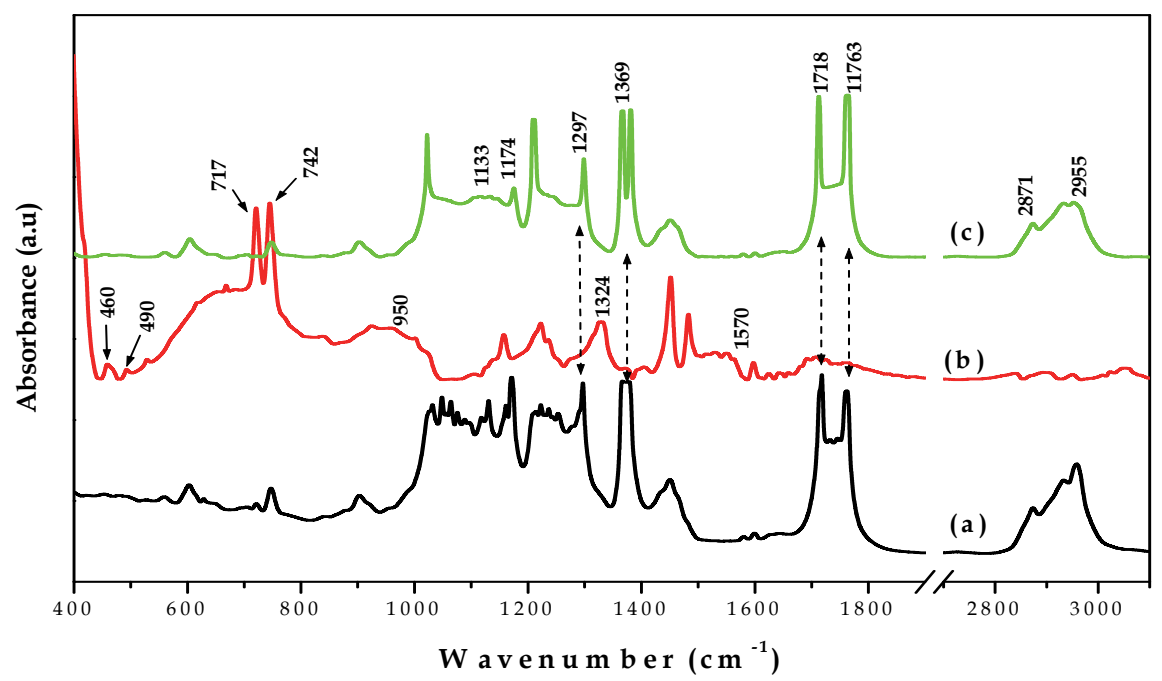

Fig. 8. Infrared spectra of OVK/SWNTs composite obtained by using chloroform (a) and chlorobenzene (b) solvents in the not annealed states and that of OVK/SWNTs obtained using chlobenzene and annealed at $333 \mathrm{~K}$.

In the full spectrum of Raman frequencies, the shape of the spectrum is conserved in both cases. However, some differences are previously observed (Zaidi et al., 2010). It is recognized that annealing induces removal of solvent effect and more establishes the SWNTs functionalization. Then, it is also mentioned as the case of SWNTs produced either by an arc discharge or pulsed lasers (Coopera et al., 2001), that a new weak band appears at $1745 \mathrm{~cm}^{-1}$. This latter can be related to the presence of oxygen in surface, probably originating from carbonyl groups or SWNTs deformation. In the other hand, the D band at $1273 \mathrm{~cm}^{-1}$ and the second order corresponding increase in intensity and undergo a slight upshift after annealing, supporting an indication of disorder in the graphite lattice or defects in nanotubes.

While the radial breathing and tangential vibration modes are apparently the same, the annealing treatment induces some differences in position and intensity which is strictly related to a better functionalization process (Figure 9).

It is shown that after annealing in both cases only the band at $166 \mathrm{c} \mathrm{cm}^{-1}$ persists. Thus, SWNTs are in the isolated form and have a mean diameter of $1.34 \mathrm{~nm}$. This indicates a more dispersion of the SWNTs into OVK matrix. For the tangential mode, we notice a slight upshift and a narrowing of the band at $1592 \mathrm{~cm}^{-1}$ by the introduction of nanotubes. In fact, for lower OVK concentrations (higher SWNTs concentrations), the quantity of OVK intercalated between nanotubes could not lead to a destruction of bundled SWNTs. The introduction of OVK into bundled (decrease of the SWNTs concentration) increases the distance between 


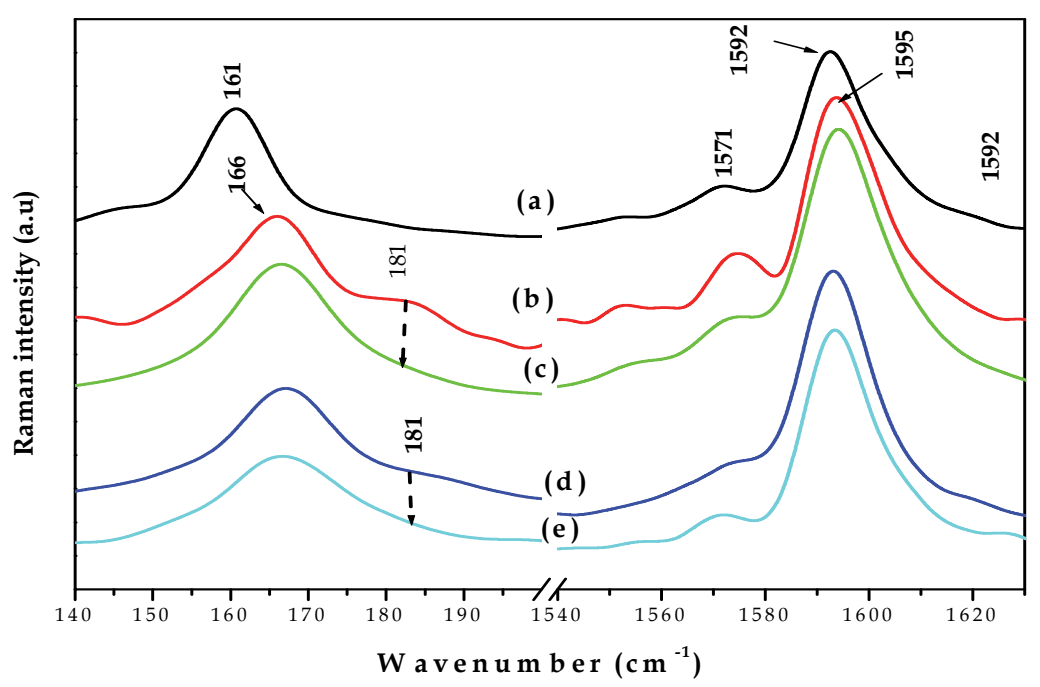

Fig. 9. Radial breathing and tangential modes in Raman spectra of: only SWNTS (a), composite OVK/SWNTs in chloroform: not heated (b) and heated at $333 \mathrm{~K}$ (c), composite OVK/SWNTs obtained in chlorobenzene: not heated (d) and heated at $333 \mathrm{~K}(\mathrm{~d})$.

nanotubes and therefore interaction between them is decreased, explaining why width of peaks is weaker when nanotubes are introduced in the OVK Matrix. Then, as it is previously described (Claye et al., 2001; Rao et al., 1997) that doping SWNTs with either electron donors or acceptors resulted in noticeable shift in certain characteristic vibrational modes, especially removing charge from SWNTs (oxidizing) results in up-shift in the G band peak around $1590 \mathrm{c}$ $\mathrm{cm}^{-1}$. This up shift is explained as the addition of some SP3 character to the SP2 hybridized orbitals. Removing electron density from these orbitals reduces the repulsion resulting in stronger net bonding and higher $\mathrm{G}$ band frequency. Moreover, the intensity of the peak at 1571 $\mathrm{cm}^{-1}$ decreases after annealing at $333 \mathrm{~K}$ illustrating a change from 2D to 3D symmetry (Eklund et al., 1995). For more details, all these results are previousely described (Zaidi, et al., 2010)

\subsection{Optical properties}

After annealing both composites, as shown in figure 10, the strength of PL quenching effect became more prounonced. The ratio $\left(\Phi F / \Phi^{\prime} \mathrm{F}\right)$ of photoluminescence intensities related to pristine OVK $(\Phi F)$ and OVK functionalized SWNTs (('F) reashes 2.7 and 1.5 respectively for both composites. Moreover, a new vibronic structure apperas at lower energy side of the emission spectrum centered at $499 \mathrm{~nm}(2.48 \mathrm{eV})$ is observed in the case of the chloroform solvent.

In fact, in both cases an energy transfer is occured as depicted by the mutual change of PL intensity between the two PL bands situated at lower wavelengths as it is reported for PPV/SWNTs (Mulazzi et al., 2006). This change implies the formation of new luminescent centre which corresponds probably to the defect related to the covalent bonding of SWNTs In fact, the band observed at $499 \mathrm{~nm}$ can be the consequence of annealing treatment or of the SWNTs addition. A more clarification can be illustrated by the PL spectra of both annealed OVK and OVK/SWNTs composite recorded at $87 \mathrm{~K}$ (Figure 11). 


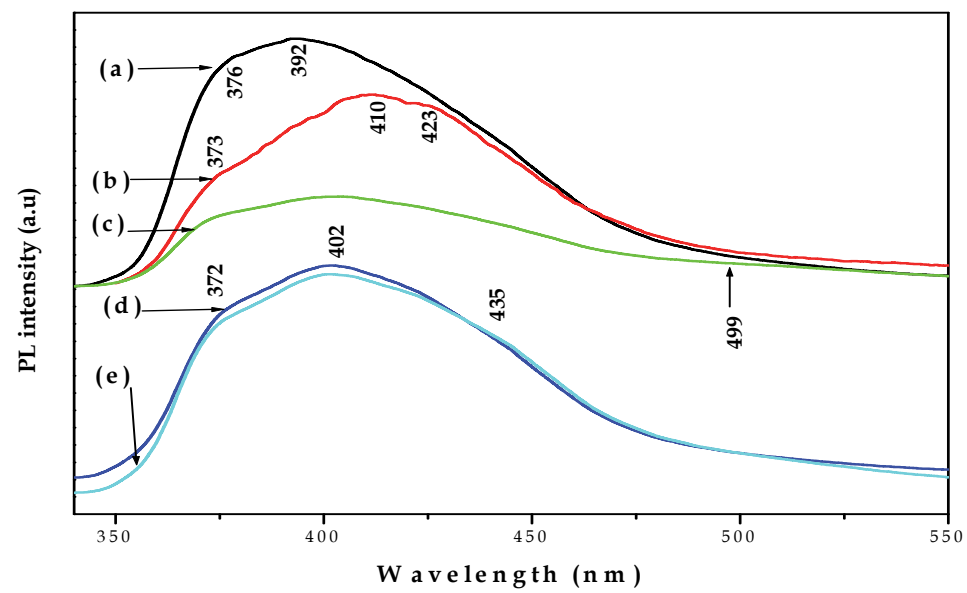

Fig. 10. PL spectra of: (a) only OVK, composite OVK/SWNTs in chloroform: not heated (b) and heated at $333 \mathrm{~K}$ (c); composite OVK/SWNTs in chlobenzene: not heated (d) and heated at $333 \mathrm{~K}(\mathrm{e})$.

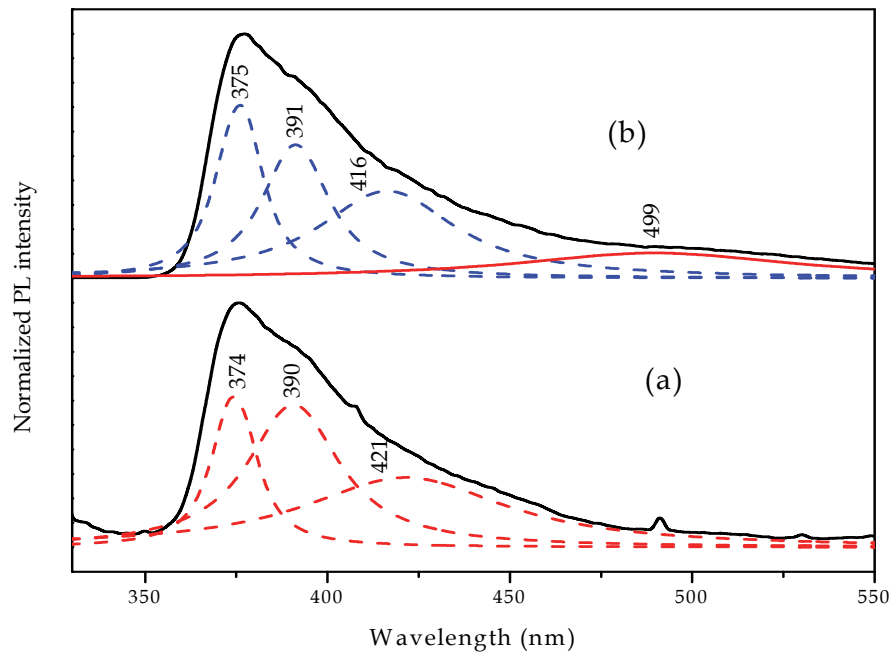

Fig. 11. PL spectra recorded at $87 \mathrm{~K}$ of annealed OVK (a) and annealed OVK/SWNTs (b).

As the new band appears only in the case of annealed OVK/SWNTs composite, it is, however, the consequence of SWNTs insertion. From figure 11, other modifications are also clearly seen. In fact, by referring to the OVK spectrum recorded at room temperature, peaks at 397 and $428 \mathrm{~nm}$ in the annealed OVK undergo a blue shift of $7 \mathrm{~nm}$ toward 390 and $421 \mathrm{~nm}$ respectively. Otherwise, the energy transfer induced by annealing is more pronounced for measurements at $87 \mathrm{~K}$.

At present, SWNTs insertion leads to additional bands in the optical absorption and photoluminescence spectra which results from an electronic interaction between OVK and 
SWNTs. A possible quenching mechanism originating from transfer of electron-hole pair (excitons) generated in OVK chain to SWNTs was already proposed (Baibarac et al. 2007b). In fact, the two PL maximums observed at 379 and $404 \mathrm{~nm}$ are considered originating from excimers formed in the partially and fully eclipsed configurations (Baibarac et al. 2007). Therefore, the variation of the PL spectra, traducing the energy transfer allows to conclude that adding SWNTs leads to the formation of fully eclipsed structure rather than partially eclipsed-one, showing that the resulting composite is homogenous and SWNTs are more dispersed in the OVK matrix.

\section{Theoretical aspect}

The structures of OVK oligomer or SWNTs either in the neutral or in the oxidized states have been fully optimized with the most popular Becke's three-parameter hybrid, B3 (Becke, 1993) with non local correlation of Lee-Yang-Parr, LYP (B3LYP) method (Lee et al., 1998). This method is based on density functional theory (DFT) for uniform electron gas and is used with the basis set such as $3-21 G^{*}$ (Pietro et al., 1982). This basis is applied to other systems based polymers (Ayachi et al., 2006; DiCesare et al., 1998; Pickholz and Santos, 1999). For the resulting composite, it has been reported that the semi-empirical Austin Model (AM1) method is an effective tool for qualitative study of functionalized nanotubes (Wongchoosuk et al., 2009). For this reason, geometry structure optimization of OVK/SWNTs composite is carried out using AM1 method (Dewar et al., 1985). On both fully geometry-optimized structures of OVK and OVK/SWNTs composite, infrared vibrationnal frequencies are carried out using respectively ab-initio Hartree-Fock (HF) and Austin (AM1) semi-empirical calculations. All these methods (AM1, ab-initio: HF and DFT) are implemented in Gaussian 98 program (Frisch et al., 1998). In the other hand, force constants of both OVK and SWNTs in the neutral and oxidized states are carried out using Mopac 2000 program (Stewart, 1999).

\subsection{OVK and SWNTs modelling structures}

In general, the vibrationnal and electronic properties of polymers can be reproduced theoretically using a typical modeling structure of maximum seven to eight units (Ayachi et al., 2006; Wang et al., 2004). For OVK, our calculations are limited to four VK units (figure $12-\mathrm{a})$. For the SWNTs, in order to obtain the real diameter of the tube $(1.3 \mathrm{~nm})$, the modeling structure is the rolling up of a graphene's sheet, having each 14 rings (figure 12-b).

\subsection{Prediction of reactive sites by the mean of force constants variation from neutral to oxidized states}

First, to rationalize the reactive sites either in OVK or SWNTs, involving the grafting reaction, force constants between neighboring atoms in both neutral and oxidized states are made on the fully optimized structures for both OVK and SWNTs (figure 13). These force constants are the mean taken from the equivalent sites in both modeling structures. As shown, only a large shift is observed for $F_{9}, F_{10}$ and $F_{11}$ in the case of OVK. These force constants are between neighboring carbon atoms in the vinylidene groups. However, in the case of nanotube the most significant variations are restricted to $F_{1}, F_{2}$ and $F_{3}$ which traduce the bonding between carbon atoms, located in the side of SWNTs. These results indicate that the grafting process take place in the nanotube side wall. 


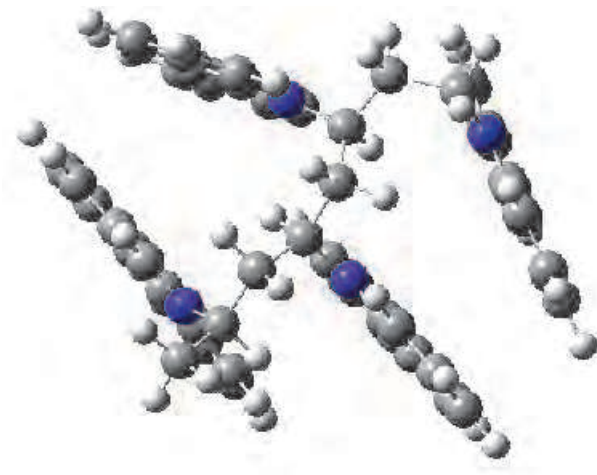

(a)

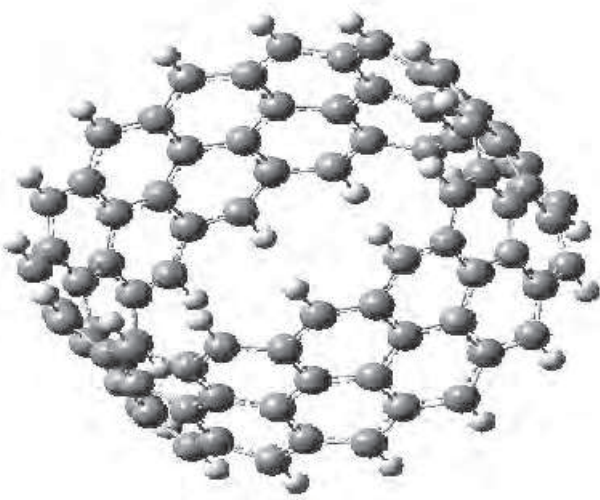

(b)

Fig. 12. OVK (a) and SWNTs (b) modelling structures optimized using DFT/B3LYP/3-21G*.

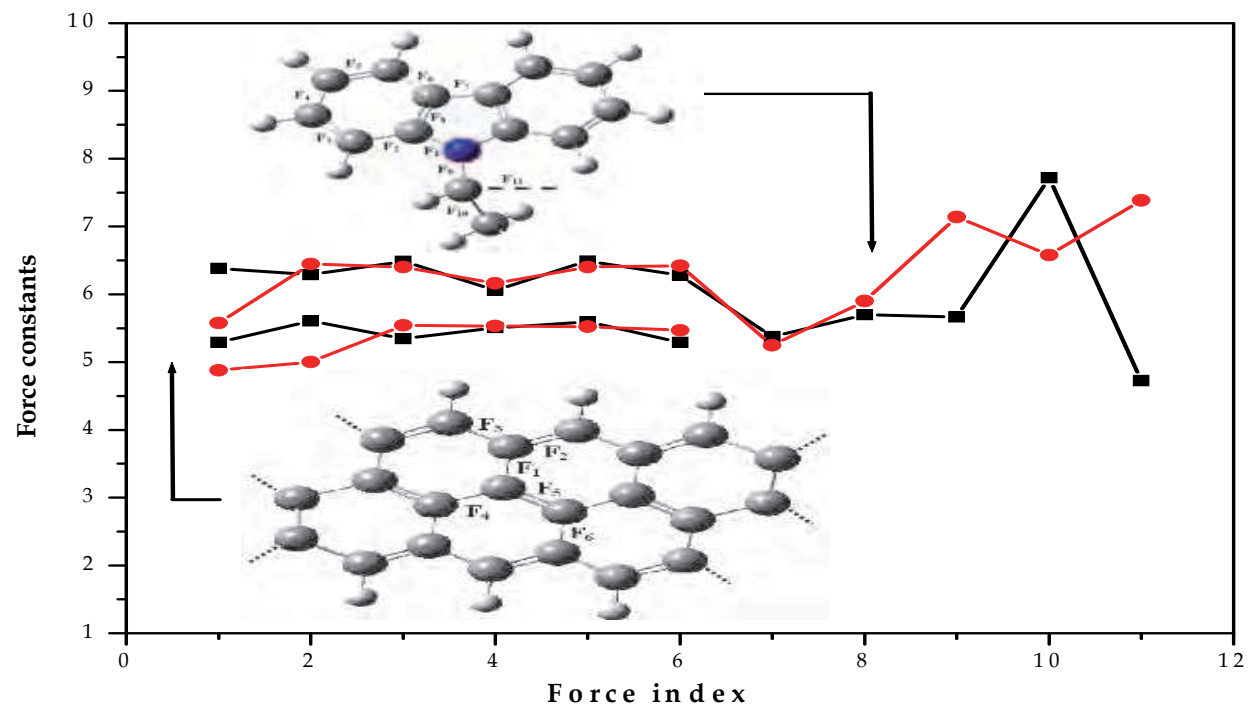

Fig. 13. Main force constants of equivalent sites in the neutral (square symbol) or oxidized (circle symbol) states of OVK and of SWNTs.

\subsection{Composite modelling structure}

Based on the above changes in force constants, we suggest a grafting reaction between vinylidene groups and the nanotube side wall. If we consider that only a few number of VK monomers are effectively bonded with SWNTs, we propose a one VK unit grafted to the nanotube as a typical modeling structure (figure 14). 


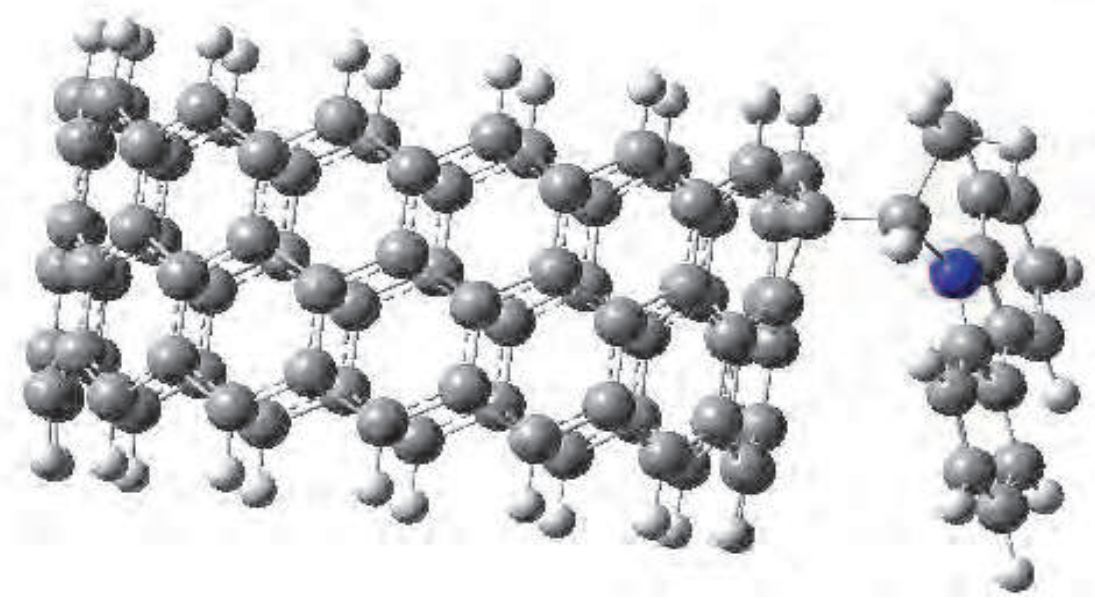

Fig. 14. OVK/SWNTs modelling structure.

\subsection{Validity of the grafting process}

To argue the above presented grafting mechanismm, our work is extended to a comparative study between experimental and theoritical vibrationnal frequencioes obtained either for OVK or OVK/SWNTs composite. Results are fully presented in our previous paper (Zaidi et al., 2010). It is demonstrated that a maximum typical shift of $40 \mathrm{~cm}^{-1}$ is observed (Zaidi et al., 2010). For OVK, both spectra exhibit nearly the same shape in band positions and intensities, except both features at 1034 and $1625 \mathrm{~cm}^{-1}$. In fact, these two bands which are respectively attributed to aromatic C-C in plane deformation and $\mathrm{C}-\mathrm{C}$ benzene stretching are strongly enhanced. This enhancement may be probably due to the absence of the steric effect. For the OVK/SWNTs, a partially accordance between experimental and theoretical band intensities is observed which might be principally due to the weight ratio ( $\left.\mathrm{W}_{\mathrm{SWNTs}} / \mathrm{W}_{\mathrm{OVK}}\right)$ that is strongly shifted from the experimental-one. In fact, two SWNTs vibrationnal modes at 1048 and $1064 \mathrm{~cm}^{-1}$ and another feature ascribed to C-C in plane deformation centered at $1118 \mathrm{~cm}^{-}$ 1 are absent in the theoretical spectra. This behavior is probably related to the SWNTs length which is not taken into account in our modeling structure.

A similar computational study describing the functionalization of carbon nanocones by free radicals (Trzaskowsk et al., 2007), predicts that single-wall graphene nanocones can be selectively functionalized by methyl radicals, as well as by other free radicals. Such functionalization has been supported by infrared spectra of these compounds as a new intense C-C bond at $1171 \mathrm{~cm}^{-1}$.

\subsection{Electronic structure}

The effect of SWNTs insertion on the electronic structure has been elucidated by geometrical optimization using DFT/B3LYP/3-21G* method. Adding SWNTs induces the modification of the electronic transitions in the absorption diagram as indicated in figure 15.

Through this energetic diagram, the most relevant transitions observed in the experimental spectra are reproduced. For OVK, the optical gap is around $3.3 \mathrm{eV}$ which is $0.2 \mathrm{eV}$ lower than that determined experimentally. In fact, this difference (LUMO-HOMO) has been 


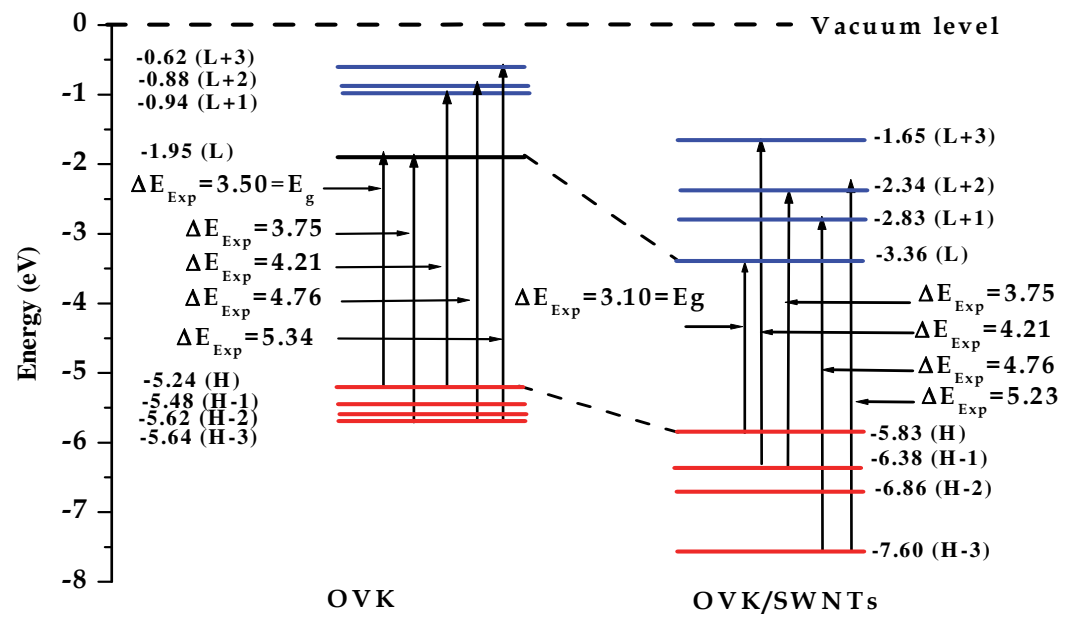

Fig. 15. Change of the electronic structure from OVK to OVK/SWNTs: (H: HOMO, L: LUMO).

calculated as a function of VK units number, using DFT/B3LYP/6-31G* method (Pana et al., 2005; Yang et al., 2006) where results are nearly the same in our case. For SWNTs modeling structure, the optical gap is $1.38 \mathrm{eV}$. The calculated gap of the resulting nanocomposite is 2.5 $\mathrm{eV}$ which is $0.6 \mathrm{eV}$ lower than that deduced from optical density measurements. This relatively large difference might be firstly due to the fact that calculations are done in gas phase. Secondly, the weight ratio $\left(\mathrm{W}_{\mathrm{SWNTS}} / \mathrm{W}_{\mathrm{OVK}}\right)$ of the model structure is largely higher than the experimental-one.

\section{Properties of SWNTs functionalized with PVK-3HT}

\subsection{Vibrational properties}

The Raman spectra of SWNTs and composite PVK-3HT/SWNTs, shown in Figure 16, contain two main features, a radial breathing mode (RBM) at low frequencies $\left(\sim 160 \mathrm{~cm}^{-1}\right)$ and tangential G-band at high frequencies $\left(1595 \mathrm{~cm}^{-1}\right)$. In addition, an intermediate feature related to the disorder or defects on SWNTS with weaker intensity is also shown at $1250 \mathrm{~cm}^{-1}$. Qualitatively, the two bands occurring at 1250 (D-band) and $1595 \mathrm{~cm}^{-1}$ (G-band) are nearly the same in all cases of composite samples as well as in the case of purified nanotubes. Qualitatively, a part the band shapes of RBM for composites sensitive to the added SWNTs, a similar up-shift of around $5 \mathrm{~cm}^{-1}$ of the band at $161 \mathrm{~cm}^{-1}$, associated to the isolated SWNTs is observed. However, the significant second band appears in composites at $179 \mathrm{~cm}^{-1}$ is attributed to the bundled SWNTS. Note that pure PVK-3HT hardly diffuses light and its spectrum has not shown.

It is well known that close examination of the radial breathing modes of the dispersed nanotubes can gives information about degrees of diameter selectivity when increasing weight of nanotubes (Dresselhaus et al., 2004). In order to appreciate the interaction within the PVK-3HT/SWNTs composites, here, we examine the radial breathing mode (RBM) features (in the first range: 145-200 $\mathrm{cm}^{-1}$ ) in SWNTs and the composites. Using the inverse 


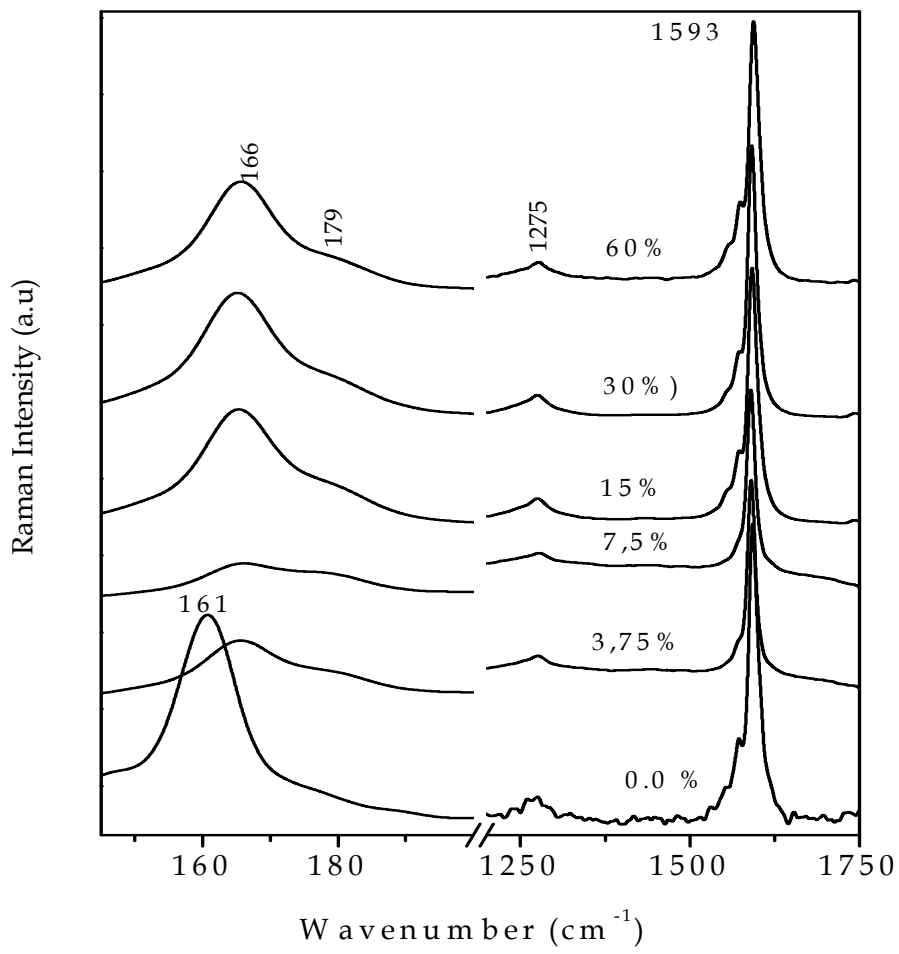

Fig. 16. Raman spectra of PVK-3HT/SWNTs composites at different weight ratio of SWNTs $(0 \%, 3.75 \%, 7.5 \%, 15 \%, 30 \%$ and $60 \%)$.

relationship between RBM mode frequency and the tube diameter (d) proposed by Rao et all (Rao et al., 1997), the two bands located at about 166 and $179 \mathrm{~cm}^{-1}$, respectively, attributed to the RBM of SWNTs activated in isolated and bundled nanotubes, indicate that the resonance Raman occurs at the diameter varying from $\sim 1.34$ to $1.25 \mathrm{~nm}$, taking into account that SWNTs have diameter around $1.39 \mathrm{~nm}$.

Figure 17 displays normalized optical infrared spectra of PVK-3HT, SWNTs and their corresponding PVK-3HT/SWNTs composite at weight ratio of $60 \%$. The room temperature infrared spectra of PVK-3HT/SWNTs composite shown in Figure 17c exhibits seven characteristic modes of PVK, at $746 \mathrm{~cm}-1$ (C-H rocking), at $921 \mathrm{~cm}^{-1}$ (C-C ring vibration), at $1022 \mathrm{~cm}^{-1}$ (aliphatic C-C rocking), at $1220 \mathrm{~cm}^{-1}$ (C-N stretching), at $1330 \mathrm{~cm}^{-1}$ (C-H deformation of vinylidene groups), at $1483 \mathrm{~cm}^{-1}\left(\mathrm{CH} 2\right.$ rocking) and at $1676 \mathrm{~cm}^{-1}$ (C-C benzene stretching). For the characteristic modes of 3-hexylthiophene (Figure 17a), the 723 $\mathrm{cm}^{-1}$ is ascribed to C-H out-of-plane bending, the $798 \mathrm{~cm}^{-1}$ is assigned to C-H out-of-plane deformation of thiophene), the $1095 \mathrm{~cm}^{-1}$ mode is from $\mathrm{C}-\mathrm{H}$ in-plane bending of the thiophene rings, the $1261 \mathrm{~cm}^{-1}$ mode corresponds to C-C stretching of the carbon which connect the thiophene rings and 1452 and $1598 \mathrm{~cm}^{-1}$ are typical ring stretch modes. The observed results support the chemical structure of copolymer under study.

According to Ref (Kim et al., 2005), infrared absorbance bands for the SWNTs are observed at 1170, 1456, 1540, and $1734 \mathrm{~cm}^{-1}$. In our case, these bands appear at 1174, 1440, 1579 and 
$1710 \mathrm{~cm}^{-1}$, respectively. Compared to the pure PVK-3HT, for the composite sample, two new pronounced features at 1049 and $1384 \mathrm{~cm}^{-1}$ appear and retain their oscillator strength. These features are assigned to $\mathrm{C}-\mathrm{C}$ vibration of SWNTs and $\mathrm{CH}_{3}$ deformation in $3 \mathrm{HT}$, respectively. Significant changes in intensity are clearly shown by adding SWNTs. Then, some bonds were loosened, whereas other vibrations were hindered when passing from pristine copolymer to the composite. Besides, we note that the most intense vibrations of PVK-3HT and those of SWNTs are found in the PVK-3HT composite spectrum. Accordingly and combined to the Raman analysis, the whole vibrational results supported a strong PVK3HT/SWNTs interaction.

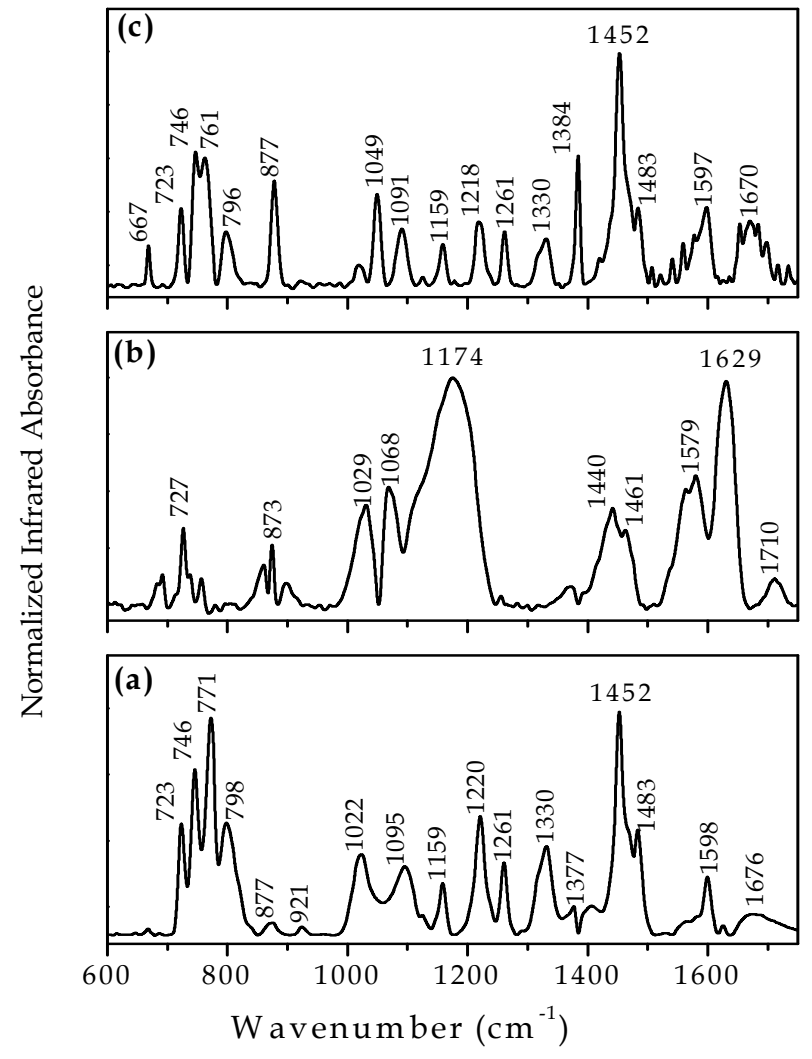

Fig. 17. Normalized infrared spectra of: PVK-3HT (a), SWNTs (b) and PVK-3HT/SWNTs composite $(60 \%)(\mathrm{c})$.

\subsection{Optical properties}

As it is noted; from vibrational propertries of the resulting composite when using the PVK3HT polymer, SWNTs exists as isolated or bundled SWNTs. However, infrared, results supports the hypothesis that there is a grafting process which takes place in the hexylthiophenes rings. From optical absorption spectra presented in figure 18, we see that PVK-H3T absorbs in two separate spectral regions. The first range is situated the UV part at 
around 240 and $300 \mathrm{~nm}$ and corresponds to the presence of bicarbazole units in the formed graft copolymer (Chemek et al., 2010). The second domain is situated in the visible part at around $430 \mathrm{~nm}$ and traduce to the presence of an extended conjugated main chain of Poly(3hexylthiophene) in the obtained copolymer (Carley et al., 2009; McCullough, 1998). In fact; from optical spectra, it appears that there is a net difference between the pristine state of the polymer and the corresponding functionalized form with SWNTs, especially for the 1.85 SWNts weight content. Thus, at the blue side of the spectrum (wavelength lower than 400) relative to the PVK polymers, bands are nearly the same. However, the band at $430 \mathrm{~nm}$ shows a sudden decrease when adding SWNTs and undergoes a continuously blueshiftwing, reflecting that there is a shortness of the effective conjugation length of these blocks (Wéry et al., 2003).

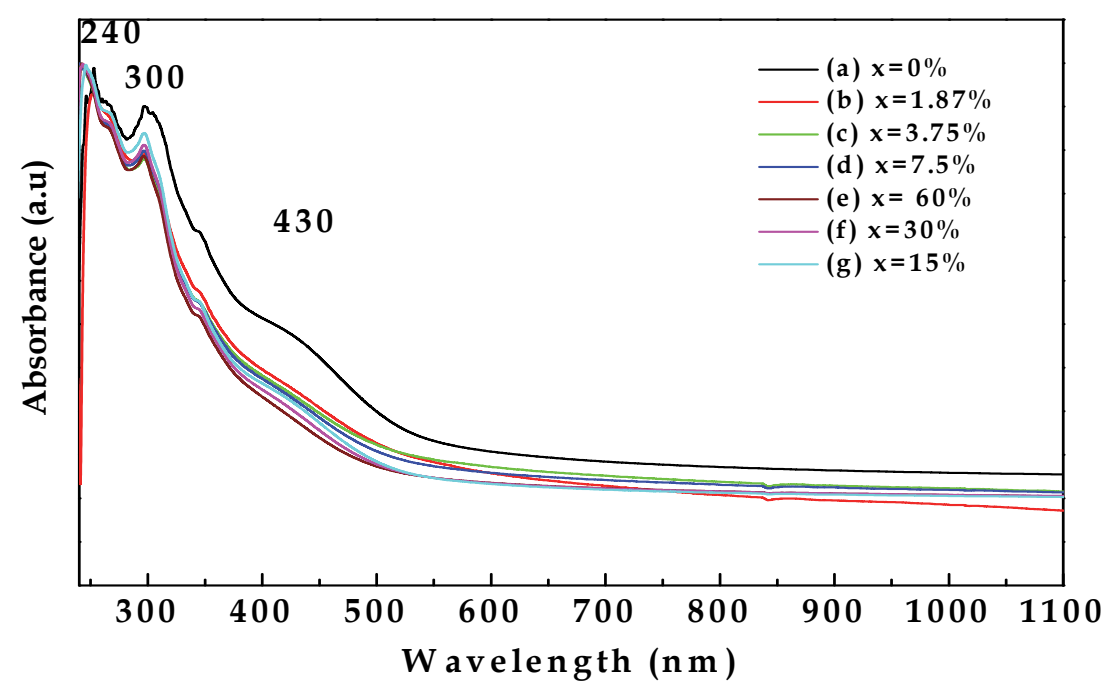

Fig. 18. Optical absorption at room temperature of pristine PVK-3HT (a) and those of PVK3HT/SWNTs composites for different SWNTs weight concentrations (x): (a) Standard PVK$3 \mathrm{HT}$, (b) $\mathrm{x}=1.87 \%$, (c) $\mathrm{x}=3.75 \%$, (d) $\mathrm{x}=7.5 \%$, (e) $\mathrm{x}=60 \%$, (f) $\mathrm{x}=30 \%$, and (g) $\mathrm{x}=15 \%$.

Although, there is no significant changes observed in optical absorption spectra when increasing SWNTs weight concentration due to the already reached percolation threshold, the large amount of SWNTs either in grafted or not, or in isolated or bundled forms can influences the excitated states of the resulting composite (Massuyeau et al., 2007). Therefore, the luminescent properties must logically undergo a dependent evolution versus the SWNTs weight concentrations. In fact, as it is previously described, carbon nanotubes can present a good network for charge migration from short to long conjugation. Particularly, at higher SWNTs concentrations, it has been demonstrated that the PL originates globally from the recombination of excitons on a majority of short conjugated segments. In this limit, statistically, the portion of long conjugated segments becomes negligible. These hot excitons can easily migrate due to their mobility (Chu et al., 2008) and then a separation process can be take place when reaching the SWNTs network. This assumption is consistent with the PL quenching, reflecting a decrease in quantum yield efficiency and the rise of the conductivity 
and the photoconductivity when $\mathrm{x}$ increases. Based on these assymptions, and for better understanding of the excited state dynamics of the prepared composites, time-resolved photoluminescence (TRPL) technique at room temperature (RT) is recorded (figure 19).

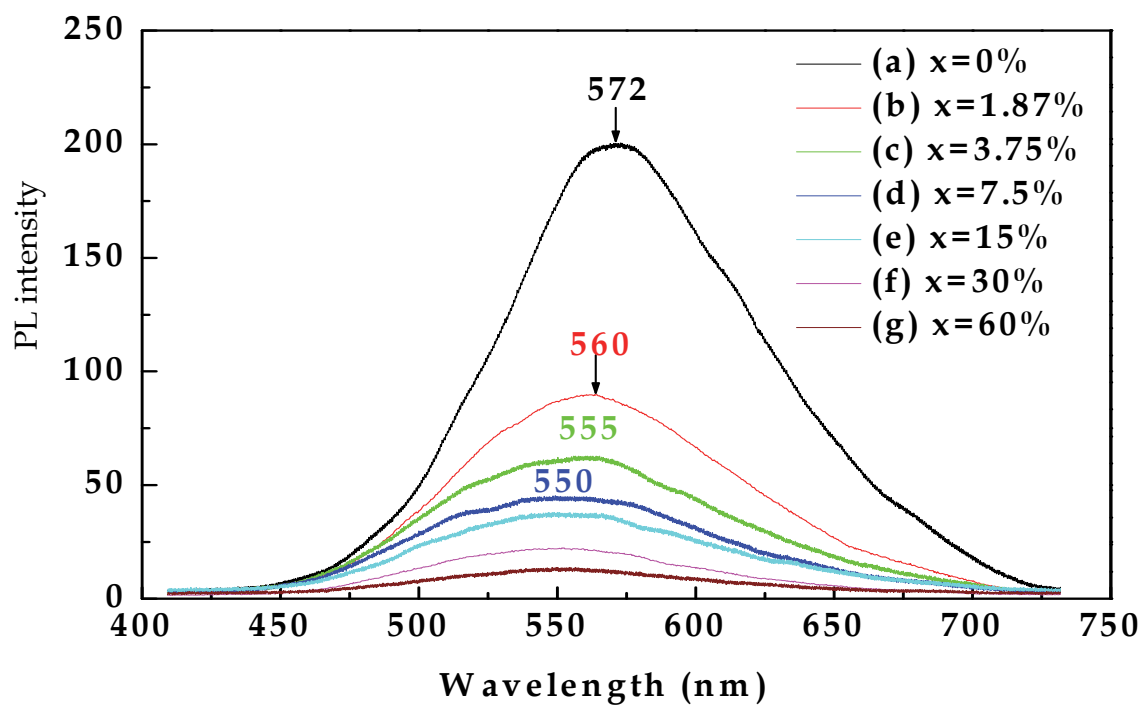

Fig. 19. Transient photoluminescence (TRPL) spectra in chloroform solution of pristine PVK3HT (a) and those of PVK-3HT/SWNT composites for different SWNTs weight concentrations (x) of SWNT: (b) $x=1.87 \%$, (c) $x=3.75 \%$, (d) $x=7.5 \%$, (e) $x=15 \%$, (f) $x=30 \%$, (g) $x=60 \%$.

All the spectra relative to all SWNTs weight concentrations are collected with excitation of $400 \mathrm{~nm}$ using seep range of $1 \mathrm{~ns}$. First, it is shown that the hexylthiophene influences the maximum emission to reach $572 \mathrm{~nm}$ rather than $300 \mathrm{~nm}$ for OVK/SWNTs. The quenching of luminescence intensity is observed with a continuous blue shiftwing of the maximum emission. The latter is detected at $572 \mathrm{~nm}$ for the pristine PVK-3HT rashes $550 \mathrm{~nm}$ for higher SWNTs contents. The blue shift observed in the TRPL spectra is in quite agreement with the observation in the optical absorption spectra, and supporting the gradual decrease of the conjugation length in PVK-3HT, backbone consequently on the lifetime of the resulting excitons.

3D-maps TRPL obtained with energy emission versus time (range 0-1 ns) and intensity in false color of PVK-3HeT and PVK-3HT/SWNTs prepared composite for different weight concentration $\times(0 \%, 1.87 \%, 7.5 \%, 15 \%, 30 \%$ and $60 \%)$ are presented in figure 20 . In this case, 3D-maps colors going from blue to red represent the increasing of the PL intensity.

To obtain a better understanding on how the SWNTs influence the excited states dynamics on the PVK-3HT, we analyzed the TRPL decays on the different prepared composites. Figure 21 shows the normalized TRPL decay dynamics on a logarithmic scale in the range of $0-1$ ns. Compared to the pristine PVK-3HT, the increase of SWNTs weight concentration progressively induces a faster decays time. A comparable behavior has been observed on the transient decays time of the prepared composite of PPV and SWNTs (Massuyeau et al., 2007). 

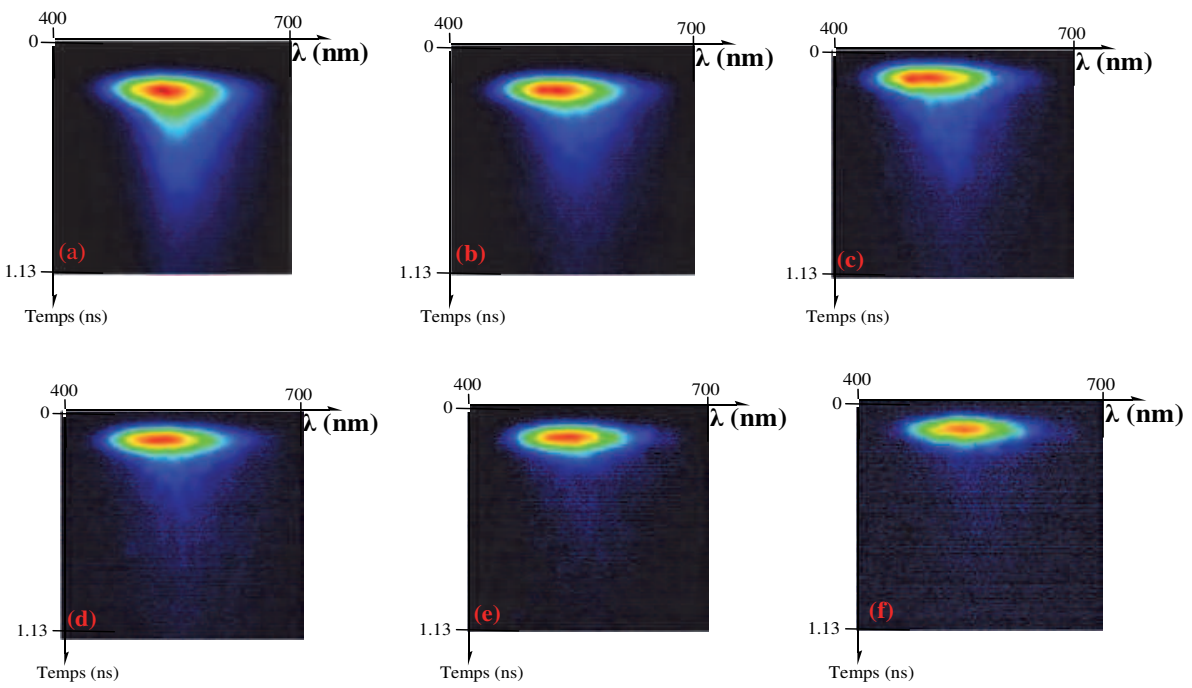

Fig. 20. Transient photoluminescence contour maps in false color of standard PVK-H3T (a) and thoseof PVK-3HT/SWNTs composites for different mass concentrations $x$ of SWNT. (a) Standard PVK-3HT, (b) $x=1.87 \%$, (c) $x=7.5 \%$, (d) $x=15 \%$, (e) $x=30 \%$, (f) $x=60 \%$.

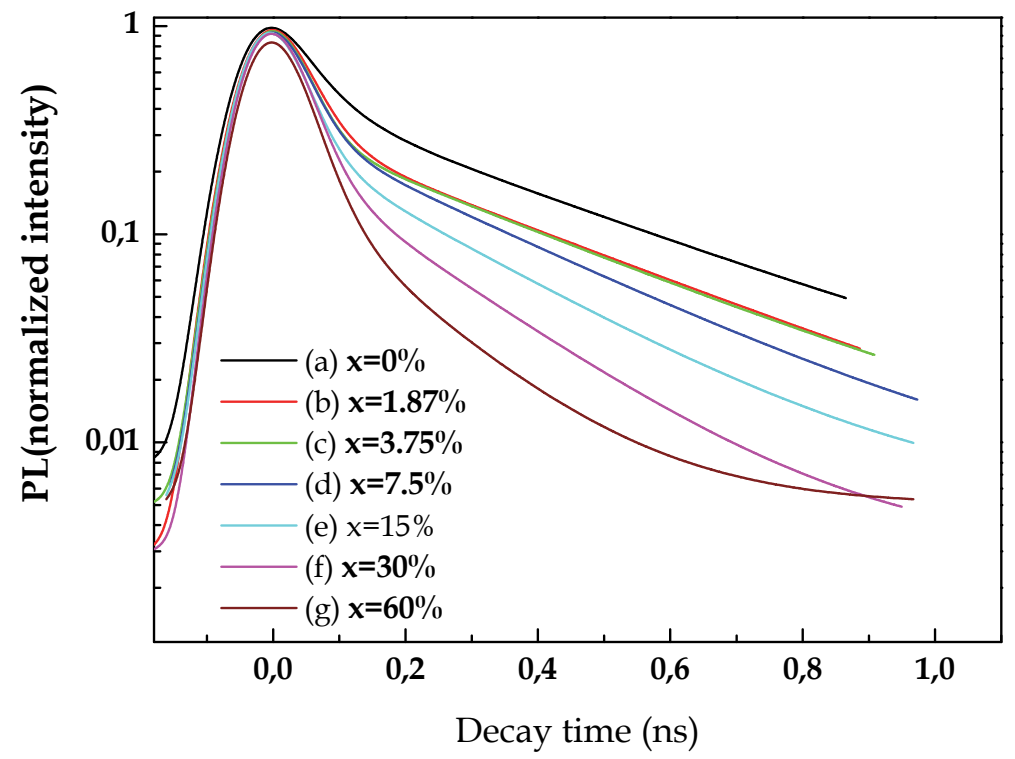

Fig. 21. Transient photoluminescence decays spectra of pristine PVK-3HT (a) and those of PVK-3HT/SWNT composites for different weight concentrations (x): (b) $x=1.87 \%$, (c) $x=3.75 \%$, (d) $x=7.5 \%$, (e) $x=15 \%$, (f) $x=30 \%$ and $(g) x=60 \%$. 
This behavior supports the hypothesis that SWNTs in the composite present a good network for the charge migration from and their presence facilate also the separation process. Thus, as $\mathrm{x}$ increase, exciton migration under light excitation is favored, resulting in carrier transport on SWNTs and PL quenching. These hot excitons can easily migrate due to their mobility (Chu et al., 2008) and then separate when reaching the SWNT network. This assumption is consistent with the PL quenching, a decrease in quantum yield efficiency and the rise of the conductivity and the photoconductivity when $\mathrm{x}$ increases.

\section{Conclusion}

The spontaneous covalent functionalization of SWNTs at the appropriate SWNTs weight concentrations with OVK has been demonstrated in a chloroform or chlorobenzene mediums, using optical absorption, photoluminescence, infrared and Raman spectroscopies. More dispersed SWNTs in the OVK matrix is obtained after annealing the resulting structure at the temperature of $333 \mathrm{~K}$. In comparison with chloroform solvent, the chlorobenzene reveals a more SWNTs dispersion process but its potential to the eventual interaction between both components is limited. Otherwice, a homogenous dispersion process is achieved for SWNTs weight concentration lower than $1.10 \%$, but without covalent attachment between both components. However, annealing the resulting composites at the moderate temperature of $333 \mathrm{~K}$ induces strong modifications on their infrared and Raman vibrational modes, involving a covalent bonding between both components. Such a covalent bonding either using chlorobenzene or chloroform is a grafting of OVK oligomers from their vinylidene groups to the nanotubes side wall. To confirm the validity of the grafting mechanism, theoretical calculations including force constants, vibrational infrared frequencies and modification of electronic structure based on the DFT methods are accomplished.

In the case of PVK-3HT, the introduction of carbon nanotube induces a great effect in the optical properties. In particular, a decrease in the absorption, blue-shift of the emission and strong PL quenching with a fast recombination of electron-hole pairs was observed for high carbon nanotube weight concentration. These behaviors are doing to the strong interaction of SWNTs with copolymer backbone, which improve exciton dissociation and better carrier transport on SWNTs and polymer backbone. Finally, the presence of nanotubes as a filler network in polymer matrix may be of importance in view of applications for solar cell development.

\section{References}

Ahuja, R.T. \& Kumar, D. (2009). Recent progress in the development of nano-structured conducting polymers/nanocomposites for sensor applications. Sens. Actuators, Vol. 136, No. 1, (February 2009), pp. (275-286). ISNN 0925-4005.

Akcelrud, L. (2003). Electroluminescent polymers, Prog. Polym. Sci. Vol. 28, No. 6, (June 2003), pp (875-962). ISNN 0079-6700/03.

Alimi, K., Safoula. G., Bernede, J. C., Rabiller, C. (1998), Degradation of poly(Nvinylcarbazole) by annealing under iodine pressure. J. Polym. Sci. Part B: Polymer Phys.; Vol. 34, No. 15,Issue 5, (April 1996), pp. (845-851),). ISNN 7 DEC 1998. 
Andrés, J.A. \& Blau, W.J. (2008). Enhanced device performance using different carbon nanotube types in polymer photovoltaic devices. Carbon, Vol. 46, No. 15, (December 2008), pp. (2067-2075). ISSN 0008-6223

Arab, H., Baitoul, M., Wery, J., Almairac, R., Lefrant, S., Faulques, E., Duvail, J. L., \& Hamedoun, M. (2005). Electrical and optical properties of PPV and single-walled carbon nanotubes composites films. Synt. Met.,Vol. 155, No.1, (October 2005), pp. (63-67). ISSN 0379-6779.

Ayachi, S., Alimi, K., Bouachrine, M., Hamidi, M., Mevellec, J.Y, \& Porte, J.P.L. (2006). Spectroscopic investigations of copolymers incorporating various thiophene and phenylene Monomers. Synt. Met., Vol. 156, No. 2-4, (February 2006), pp. (318-326). ISSN 0379-6779.

Baibarac, M., Baltog, I., Lefrant, S. \& Romero, P.G. (2007). Spectroscopic evidence for the bulk polymerization of $\mathrm{N}$-vinyl carbazole in the presence of single-walled carbon nanotubes. Polym., Vol. 48, No. 18, (August 2007) ,pp. (5279-5288). ISSN 0032-3861.

Barlier, V., Bounor-Legaré, V., Boiteux, G., Davenas, J., Slazak, A., Rybak. A \& Jung, J. (2009). Photogeneration and photovoltaic effect in poly(N-vinylcarbazole): TiO2 bulkheterojunction elaborated by hydrolysis-condensation reactions of $\mathrm{TiO} 2$ precursors. Synth. Met. Vol. 159, No. 5-6, (March 2009 ), pp. (508-512). ISNN 03796779 .

Becke, A.D. (1993). Density-functional thermochemistry. III. The role of exact exchange. J. Chem. Phys., Vol. 98, No. 7, (1993), pp. (5648-2652). ISSN 0021-9606.

Bendiab, N., Anglaret, E., Bantignies, J.-L., Sauvajol, J.L., Petit, P., \& Mathis, C. (2002). Stoichiometry dependence of the Raman spectrum of Li-doped single-wall carbon nanotubes. Physica B, Vol. 323, No. 1-4, (October 2002), pp. (259-261). ISSN 09214526.

Bertoncello, P., Notargiacomo, A., Erokhin, V., \& Nicolini, C. (2006). Functionalization and photoelectrochemical characterization of poly[3-3-(vinylcarbazole)] multi-walled carbon nanotube (PVK-MWNT) Langmuir-Schaefer films. Nanotechnol., Vol. 17, No. 3, (February2006), pp. (699-705). ISSN 0957-4484.

Bondavalli, P., Legagneux, P., \& Pribat, D. (2009). Carbon nanotubes based transistors as gas sensors: State of the art and critical Review. Sens. Actuators, Vol. 140, No. 1, (June 2009), pp. (304-318). ISSN 0925-4005.

Brown, M. J., Anderson, D. P., Justice, R. S., Lafdi, K.., Belfor, M., Strong, L. K., Schaefe, W. D., (2005). Hierarchical morphology of carbon single-walled nanotubes during sonication in an aliphatic diamine, Polym. Vol. 46, No. 24 (November 2005), pp.(10854-10865). ISSN 0032-3861.

Byron, P. R., Hubert, P., Salvetat J.-P., Zalamea, L., (2006). Flexural deflection as a measure of van der Waals interaction forces in the CNT array. Compos. Sci. and Tech. 66, No 9 (July 2006) pp. (1125-1131). ISSN 266-3538.

Cai, W., Gong, X. \& Cao, Y. (2010). Polymer solar cells: Recent development and possible routes for improvement in the performance. Sol. Energy Mater. Sol. Cells, Vol. 94, No.2, (Febrary 2010), pp 114-127. ISNN 0927-0248.

Canestraro, C.D., Schnitzler, M.C., Zarbin, A.J.G., da Luz, M.G.E., \& Roman, L.S. (2006). Carbon nanotubes based nanocomposites for Photocurrent improvement. Appl. Surf. Sci., Vol 252, No. 15, (May 2006), pp. (5575-5578). ISSN 0169-4332. 
Capek, I. (2009). Dispersions, novel nanomaterial sensors and nanoconjugates based on carbon nanotubes. Adv. Colloid Interface Sci.,Vol. 150, No. 2, (September 2009), pp. (63-89). ISSN 0001-8686.

Caste, C., Castelvetro, V., Ciardelli, F., Colligiani, A., Mazzotta. A., Michelotti, D., Ruggeri, G., Veracini, C.A; (2003). Photoconductive films of poly-N-vinylindole-based blends for high-voltage photorefractive electrooptic cells. Synth. Met., 138, No 1-2 (June 2003), pp. (341-345). ISSN 0379-6779.

Cathcart, H., Coleman J. N.; (2009) Quantitative comparison of ultracentrifuged and diluted single walled nanotube dispersions: differences in dispersion quality. Chem. Phy. Lett. Vol. 474, No 1-3 (May 2009), pp. 122-126. ISSN 0009-2614.

Chapelle, M.L., Lefrant, S., Journet, C., Mase, W., Bernier, P., \& Loiseau, A. (1998). Raman Studies on single Walled carbon nanotubes produced by the electric arc technique. Carbon, Vol. 36, No. 5-6, (1998), pp. (705-708). ISSN 0008-6223.

Chemek, M., Wéry, J., Bouachrine, M., Paris, M., Lefrant, S. \& Alimi, K. (2010). Synthesis and characterization of novel graft copolymers of Poly(N-vinylcarbazole) and Poly(3-methylthiophene) for optoelectronic applications. Synth. Met. Vol.160, No. 21-22, (November 2010), pp (2306-2314). ISNN 0379-6779.

Chen, B., Inoue, S., \& Ando, Y. (2009). Raman spectroscopic and thermogravimetric studies of high-crystallinity SWNTs synthesized by FH-arc discharge method. Diamond Relat. Mater.,Vol. 18, No. 5-8, (May-August 2009), pp. (975-978). ISSN 0925-9635.

Chu, W., Wang, Y., S., Li, F., Feng, L. W. \& Gong, Q., (2008). Steady-state and transient-state optical properties of a charge-transfer composite material MO-PPV/SWNTs. Chem. Phys. Lett. Vol. 451, (Jannary 2008), pp. (116-120). ISNN 0009-2614.

Claye, A., Rahman, S., Fischer, J.E., Sirenko, A., Sumanasekera, G.U. \& Eklund, P.C. (2001). Insitu Raman scattering studies of alkali-doped single wall carbon nanotubes. Chem. Phys. Lett., Vol. 333, No. 1-2, (January 2001), pp. (16-22). ISSN 0009-2614.

Coopera, C.A., Younga, R.J., \& Halsallb, M. (2001). Investigation into the deformation of carbon nanotubes and their composites through the use of Raman spectroscopy. Compos. PartA, Vol. 32, No. 3-4, (March, April 2001), pp. (401-411). ISSN 1359-835X.

Craley, C. R., Zhang, R., Kowalewski, T., McCullough, R. D. \& Stefan, M, C. (2009). Regioregular Poly(3-exylthiophene) in a Novel Conducting Amphiphilic Block Copolymer. Macromol. Rapid Commun. Vol. 30, No. 2, (Jannary 2009) pp (11-16). ISNN 200800487.

Dewar, M.J.S., Zoebish, E.G., Healy, E.F., \& Stewart, J.J.P. (1985). Development and use of quantum mechanical molecular models. 76. AM1: a new general purpose quantum mechanicalmolecular model. J. Am. Chem. Soc., Vol. 107, No. 13, (1985) ,pp. (39023909).

DiCesare, N., Belletete, M., Marrano, C., Leclerc, M., \& Durocher, G. (1998). Conformational Analysis (ab initio HF/3-21G*) and Optical Properties of Symmetrically Disubstituted Terthiophenes. J. Phys. Chem. A., Vol. 102, No. 26, pp. (5142-5149). ISSN 1089-5639.

Dobruchowska, E., Glowacki, I., Ulanski, J., Sanetra, J. \& Pielichowski, J. (2008). Thermoluminescence of poly(9-vinylcarbazole) modified by substitution with halogens. J.Chem. Phys., Vol. 348, No. 1-3, (June 2008), pp. (249-253). ISSN 03010104 . 
Dresselhaus, M.S., Dresselhaus, G., Saito, R., \& Jorio, A. (2005). Raman spectroscopy of carbone naotubes. Phys. Rep., Vol. 409, No. 2, (March 2005), pp. (47-99). ISSN 03701573.

Eklund, P.C., Holden, J.M. \& Jishi, R.A. (1995). Vibrational modes of carbon nanotubes; spectroscopy and theory. Carbon, Vol. 33, No. 7, (1995), pp. (959-972). ISSN 00086223.

Fantini, C., Cassimiro, J., Peressinotto, V.S.T., Plentz, F., Filho, A.G.S., Furtado, C.A., \&Santos, A.P. (2009). Investigation of the light emission efficiency of single-wall carbon nanotubes wrapped with different surfactants. Chem. Phys. Lett., Vol. 473, No. 1-3, (April 2009), pp. (96-101). ISSN 0009-2614.

Frisch, M.J., Trucks, G.W., Schlegel, H.B., Scuseria, G.E., Robb, M.A., Cheeseman, J.R., Zakrzewski, V.G.Jr., Montgomery J.A., Stratmann, R.E., Burant, J.C., Dapprich, S., Millam, J.M., Daniels, A.D., Kudin, K.N., Strain, M.C., Farkas, O., Tomasi, J., Barone, V., Cossi, M., Cammi, R., Mennucci, B., Pomelli, C., Adamo, C., Clifford, S., Ochterski, J., Petersson, G.A., Ayala, P.Y., Cui, Q., Morokuma, K., Malick, D.K., Rabuck, A.D., Raghavachari, K., Foresman, J.B., Cioslowki, J., Ortiz, J.V., Stefanov, B.B., Liu, G., Liashenko, A., Piskorz, P., Komaromi, I., Gomperts, R., Martin, R.L., Fox, D.J., Keith, T., Al-Laham, M.A., Peng, C.Y., Nanayakkara, A., Gonzalez, C., Challacombe, M., Gill, P.M.W., Johnson, B., Chen, W., Wong, M.W., Andres, J.L., Head-Gordon, M., Replogle, E.S., Pople, J.A., GAUSSIAN 98, Gaussian Inc., Pittsburgh, PA (1998).

Ganter, M.J., Landi, B.J., Worman, J.J., Schauerman, C.M., Cress, C.D., \& Raffaelle, R.P. (2009). Variation of single wall carbon nanotube dispersion properties with alkyl amide and halogenated aromatic solvents. Mater. Chem. Phys. Vol. 116, No. 1, (July 2009), pp. (235-241). ISSN 0254-0584.

Huang, J. E., Li, X.H., Xu, J.C. \& Li, H.L. (2003). Well-dispersed single-walled carbon nanotube/polyaniline composite films. Carbon, Vol. 41, No. 14, (2003), pp. (27312736). ISSN 0008-6223.

Journet, C., Alvarez, L., Micholet, V., Guillard, T., Chapelle, M. L., Anglaret, E., Sauvajol, J.L., Lefrant, S., Bernier, P., Laplaze, D., Flamant, G., \& Loiseau, A. (1999). Single walled carbon nanotubes: two ways of production. Synt. Met., Vol. 103, No. 1-3, (June 1999), pp. (2488-2489).ISSN 0379-6779.

Kawano, K., Sakai, J., Yahiro, M. \& Adachi, C. (2009). Effect of solvent on fabrication of active layers in organic solar cells based on poly(3-hexylthiophene) and fullerene derivatives. Sol. Energy Mater. Sol. Cells, Vol. 93, No. 4, (April 2009), pp. (514-518). ISNN 0927-0248.

Kim, U. J.; Liu, X. M.; Furtado, C. A.; Chen, G.; Saito, R.; Jiang, J.; Dresselhaus, M. S, Eklund, P. C. (2005). Infrared-Active Vibrational Modes of Single-Walled Carbon Nanotubes. Phys. Rev. Lett., Vol. 95, No. 15, (October 2005), pp. (157402). ISSN 101103.

Lau, K.-t.; Lu, M.; Lam C.-k., Cheung H.-y., Sheng; F.-L, Li, H.-L., (2005). Thermal and mechanical properties of single-walled carbon nanotube bundle-reinforced epoxy nanocomposites: the role of solvent for nanotube dispersion. Compos. Sci. and Tech. Vol. 65, No. 5 (April 2005) pp. (719-725). ISSN 0266-3538. 
Lee, C., Yang, W., \& Parr, R.G. (1998). Development of the Colle-Salvetti correlation-energy formula into a functional of the electron density. Phys. Rev. B., Vol. 37, No. 2, (January 1988), pp. (785-789).

Li, C., Liu, C. , Li, F. \& Gong, Q. (2003). Optical limiting performance of two soluble multiwalled carbon nanotubes. Chem. Phys. Lett., Vol. 380, No 1-2, (October 2003), pp. (201-205). ISSN 0009-2614.

Massuyeau, F., Aarab, H., Mihut, L., Lefrant, S., Faulques, E. \& Wéry. J., (2007). Optical Properties of Poly(para-phenylenevinylene) and single-walled Carbon Nanotube composite films: effects of conversion temperature, prucursor dilution and nanotube concentrations. Phys.Chem.C. Vol. 111, (September 2007), pp. ( 1511115118). ISNN jp074635x CCC.

McCullough, R. (1998). The Chemistry of Conducting Polythiophenes. Adv. Mater, Vol. 10, No. 2, (Jannary 1998), pp. (93-116). ISNN 0201-0093.

Meng, L., Fu, C., \& Lu, Q. (2009). Advanced technology for functionalization of carbonNanotubes. Prog. Nat. Sci., Vol. 19, No. 7, (July 2009), pp. (801-810). ISSN 1002-0071.

Moisan ,J.-Y; Andre, B; Lever, R; (1991) Xerographic dark discharge of PVK-TNF photoconductive. Mater. Chem. Phys., Vol. 153, No. 1-2, (May 1991) pp. 305-312. ISSN 0301-0104.

Mulazzi, E., Perogo, R., Wery, J., Mihut, L., Lefrant, S., \& Faulques, E. (2006). Evidence of temperature dependant charge migration on conjugated segment in poly-pphenylene vinylene and single-walled carbon nanotubes. J. chem. phys., Vol. 125, No. 1, (July 2006), pp. (1-014703.6). ISSN 0021-9606.

Nam, N.P.H., Cha, S.W., Kim, B.S., Choi, S.H., Choi, D.S. \& Jin, J. I. (2002).Photoluminescence and electroluminescence properties of poly(9vinylcarbarzole) doped with Anthracence derivatives containing bis(ethynylphenyl oxadiazole) or bis(vinylphenyl oxadiazole) substituents. Synt. Met., Vol. 130, No. 3 , (October 2002), pp. (271-277). ISSN 0379-6779.

On chan, H. S. \& Ng, S. C. (1998). Synthesis, characterization and applications of thiopheneBased functional polymers. Prog. Polym. Sci. Vol. 23, No.7, (Novembre 1998), pp. (1167-1231). ISNN 0079-6700.

Pana, J.-H., Chiub, H.-L., \& Wang, B.-C. (2005). Theoretical investigation of carbazole derivatives as hole-transporting materials in OLEDs. J. Mol. Struct.: THEOCHEM, Vol. 725, No. 1-3, (July 2005), pp. (89-95). ISSN 0166-1280.

Park, C., Ounaies, Z.,Watson, A. K., Crooks, E. R., Smith, J. J., Lowther, E.S., Connell, W.J., Siochi, J. E., Harrison, S J., Clair, L.S. T., (2002). Dispersion of single wall carbon nanotubes by in situ polymerization under sonication. Chem. Phys. Lett. Vol. 364, N.o 3-4, (October 2002), pp. (303-308). ISSN 0009-2614.

Pei, N., Zhang, X.T., Li, Y.C., Huang, Y.B. \& Mo, Y.J. (1999). A study of poly (vinylcarbazole) adsorbed on silver surface by SERS. Vibra. Spectro., Vol. 21, No. 1-2, (December 1999), pp. (39-43). ISSN 0924-2031.

Pickholz, M., \& dos Santos, M.C. (1999). Interchain and correlation effects in oligothiophenes. Synt. Met., Vol. 101, No. 1-3, (May 1999), pp. (528-529). ISSN 03796779.

Pietro, W.J., Francl, M.M., Hehre, W.J., Defrees, D.J., Pople, J.A. \& Binkley, J.S. (1982). Selfconsistent molecular orbital methods. 24. Supplemented small split-valence basis 
sets for second-row elements. J. Am. Chem. Soc., Vol. 104, No. 19, (1982), pp. (50395048).

Popov, V.N. (2003). Carbon nanotubes : properties and application. Mater. Sci. Eng., Vol. 43, No. 3, (January 2004), pp. (61-102). ISSN 0927-796X.

Qui, Y., Duan, L., Hu, Xiaoming, Zhang, D., Zheng, M. \& Bai, F. (2001). Electroluminescence enhancement by blending PVK with an alternating copolymer containing triphenylamine and phenylene units. Synth. Met.,Vol.123, No. 1, (August 2001), pp (39-42). ISNN ) 0379-6779.

Rao, A. M., Richter, E., Bandow, S., Chase, B., Eklund, P. C., Williams, K. A., Fang, S., Subaswamy, K., Menon, M., Thess, A., Smalley, R. E., \& Dresslhaus, G. (1996). Diameter-Selective Raman Scattering from Vibrational Modes in Carbon Nanotubes. Sci., Vol. 275, No. 5297, (January 1997), pp. (187-191). ISSN 0036-8075.

Rao, A.M., Eklund, P.C., Bandow, S., Thess, A. \& Smalley, R.E. (1997). Evidence for chargetransfer in doped carbon nanotube bundles from Raman scattering. Nature, Vol. 388, No. (July 1997), pp. (257-259). ISSN 0028-0836.

Rao, A.M. , Chen, J. , Richter, E. , Schlecht, U. , Eklund, P.C. , Haddon, R.C., Venkateswaran, U.D., Kwon, Y. K. \& Tomanek, D. (2001). Effect of van der Waals Interactions on the Raman Modes in Single Walled Carbon Nanotubes. Phys. Rev. Lett., Vol. 86, No. 17, (April 2001), pp. (3895-3898). ISSN 0031-9007.

Ryabenko, A.G., Dorofeeva, T.V., \& Zvereva, G.I. (2004). UV-VIS-NIR spectroscopy study of sensitivity of single-wall carbon nanotubes to chemical processing and Van-derWaals SWNT/SWNT interaction. Verification of the SWNT content measurements by absorption Spectroscopy. Carbon,Vol. 42, No. 8-9, (2004), pp. (1523-1535). ISSN 0008-6223

Safoula, G., Touihri, S., Bernede, J.C., Jamali, M., Rabiller, C., Molinie, P., \& Napo, K. (1998). Properties of the complex salt obtained by doping the poly(N-vinylcarbazole) with bromine. Polym., Vol. 40, No. 2, (1999), pp. (531-539). ISSN 0032-3861.

Saunders, B.R., Turner, M.L. (2007). Nanoparticle-polymer photovoltaic cells. Adv. Colloid Interface Sci.,Vol. 138, No. 1, (April 2008), pp. (1-23). ISSN 0001-8686.

Schroder, E.; Hyldgaard, P. (2003) Van der Waals interactions of parallel and concentric nanotubes, Mat. Sci. Eng., C 23, No 6-8 (December 2003), pp. (721-725). ISSN 09284931.

Stewart, J.J.P., Quantum chemistry program exchange, No. 455, Mopac 2000 (C) Fujitsu limited, Tokyo, Japan (1999).

Tam, P.D., Hieu, N.V., Chien, N.D., Le, A.-T., \& Tuan, M.A. (2009). DNA sensor development based on multi-wall carbon nanotubes for label-free influenza virus (type A) detection. J. Immunol. Methods, Vol. 350, No.1-2, (October 2009), pp. (118124). ISSN 0022-1759.

Tang, A.; Teng, F., Xiong; S., Hou, Y.; (2008). Spectral studies of thin films based on poly(Nvinylcarzole) and red dopant (January 2008), Appl. Surf. Sci. 254 (January 2008), issue 7 pp. (2043-2047). ISSN 0169-4332.

Touhri, S., Safoula, G., Leny, R., Bernede, J.C., (1997). Comparison of the properties of iodine-doped poly(N-vinylcarbazole)(PVK) thin films obtained by evaporation of pure powder followed byiodine post-deposition doping and iodine pre-doped powder. Thin Solid films, vol 304, No (April 1997), pp. (16-23).ISSN 0040-6090. 
Tripisciano, C., Kraemer, K., Taylor, A., \& Palen, E.B. (2009). Single-wall carbon nanotubes based anticancer drug delivery system. Chem. Phys. Lett., Vol. 478, No. 4-6, (August 2009), pp.(200-205). ISSN 0009-2614.

Trzaskowski, B., Jalbout, A.F. \& Adamowicz, L. (2007). Functionalization of carbon nanocones by free radicals: A theoretical study. Chem. Phys. Lett., Vol. 444, No. 4-6, (August2007), pp. (314-318). ISSN 0009-2614.

Upadhyay, P., Ramrakhiani, M., \& Bisen, D.P. (2008). Photoluminescence and electroluminescence studies of polyvinylcarbazole films. J. Lumines., Vol. 128, No. 10, (October 2008), pp. (1595-1600). ISSN 0022-2313.

Wang, C., Guo, Z.X., Fu, S., Wu, W. \& Zhu, D. (2004). Polymers containing fullerene or carbon nanotube structures. Prog. Polym. Sci., Vol. 29. No. 11, (November 2004), pp. (1079-1141). ISSN 0079-6700.

Wéry, J., Aarab, H., Lefrant, S., Faulques, E., Mulazzi, E. \& Perego, R. (2003). Photoexcitations in compositrs of poly(paraphenylene vinylene) and single-walled carbon nanotubes. Phys. Rev. B. Vol. 67, (March 2003), pp. (115202-115207). ISNN 115202(6).

Wise, K.E., Park, C., Siochi, E.J., \& Harrison, J.S. (2004). Stable dispersion of single wall carbon nanotubes in polyimide: The role of non covalent interactions. Chem. Phys. Lett. Vol.391, No. 4-6, (June 2004). pp. ( 207-211). ISSN 0009-2614.

Wongchoosuk, C., Udomvech, A., \& Kerdcharoen, T. (2009). The geometrical and electronic structures of open-end fully functionalized single-walled carbon nanotubes. Curr. App. Phys., Vol. 9, No. 2, (March 2009), pp. (352-358). ISSN 1567-1739.

Wu, W., Li, J., Liu, L., Yanga, L., Guo, Z.-X., Dai, L., \& Zhu, D. (2002). The photoconductivity of PVK-carbon nanotube blends. Chem. Phys. Lett.,Vol. 364, No.1-2, (September 2002), pp. (196-199). ISSN 0009-2614.

Wu, H.X., Qiu, X.Q., Cai, R.F. \& Qian, S.X. (2007). Poly(N-vinyl carbazole)-grafted multiwalled carbon nanotubes: Synthesis via direct free radical reaction and optical limiting properties. App. Surf. Sci., Vol. 253, No. 11, (March 2007), pp. (5122-5128). ISSN 0169-4332.

Yang, L., Feng, J.-K. , Ren, A.-M. , Sun, J.-Z. (2006). The electronic structure and optical properties of carbazole-based conjugated oligomers and polymers, a theoretical investigation. Polym. Vol. 47, No. 4, (February 2006), pp. (1397-1404). ISSN 00323861.

Yap, C.C., Yahaya, M. \& Salleh, M.M. (2009). Influence of tetrabutylammonium hexafluorophosphate (TBAPF6) doping level on the performance of organic light emitting diodes based on PVK:PBD blend films. Curr. App. Phys., Vol. 9, No. 4, pp. (Jully 2009), ( 722-726). ISNN 0379-6779.

Yoon, S. J., Chun, H., Lee, M. S. \& Kim. N. (2008). Preparation of poly(N-vinylcarbazole) (PVK) nanoparticles by emulsion polymerization and PVK hollow particles. Synth. Met. Vol. 159, No.5-6, ( March 2009) pp. (518-522). ISNN 0254-0584.

Yuna, D., Feng, W., Wu, H., Li, B. , Liu, X., Yi, W., Qiang, J., Gao, S., \& Yan, (2008) Controllable functionalization of single-wall carbon nanotubes by in situ polymerization method for organic photovoltaic devices. Syn. Met. Vol. 158, No. 2124, (December 2008), pp. (977-983). ISSN 0379-6779.S. 
Zaidi, B., Bouzayen, N., Wéry, J., Alimi, K., (2010). Grafting of oligo-N-vinyl carbazole on single walled carbon nanotubes. J. Mol. Struc., vol. 971, No. 1-3 (May 2010), pp. (7180). ISSN 0022-2860.

Zaidi, B., Bouzayen, N., Wéry, J., Alimi, K., (2011). Annealing treatment and carbon nanotubes concentration effects on the optical and vibrational properties of single walled carbon nanotubes functionalized with short oligo-N-vinyl carbazole. Mter. Chem.phys., vol. 126, No. 1-2 (March 2011), pp. (417-423). ISSN 0254-0584.

Zheng, Q., Xia, D., Xue, Q., Yan, K., Gao, X., \& Li, Q. (2008). Computational analysis of effect of modification on the interfacial characteristics of a carbon nanotube-polyethylene composite system. Appl. Surf. Sci., Vol. 255, No. 6, (January 2009), pp. (3534-3543). ISSN 0169-4332.

Zhu, H., Wei, J., Wang, K. \& Wu, D. (2009). Applications of carbon materials in photovoltaic solar cells. Sol. Energy Mater. Sol. Cells, Vol. 93, No. 9, (Septembre 2009), pp 14611470. ISNN 0927-0248. 


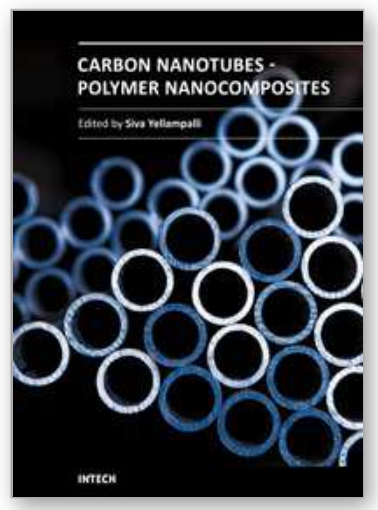

\section{Carbon Nanotubes - Polymer Nanocomposites}

Edited by Dr. Siva Yellampalli

ISBN 978-953-307-498-6

Hard cover, 396 pages

Publisher InTech

Published online 17, August, 2011

Published in print edition August, 2011

Polymer nanocomposites are a class of material with a great deal of promise for potential applications in various industries ranging from construction to aerospace. The main difference between polymeric nanocomposites and conventional composites is the filler that is being used for reinforcement. In the nanocomposites the reinforcement is on the order of nanometer that leads to a very different final macroscopic property. Due to this unique feature polymeric nanocomposites have been studied exclusively in the last decade using various nanofillers such as minerals, sheets or fibers. This books focuses on the preparation and property analysis of polymer nanocomposites with CNTs (fibers) as nano fillers. The book has been divided into three sections. The first section deals with fabrication and property analysis of new carbon nanotube structures. The second section deals with preparation and characterization of polymer composites with CNTs followed by the various applications of polymers with CNTs in the third section.

\section{How to reference}

In order to correctly reference this scholarly work, feel free to copy and paste the following:

K. Alimi, B. Zaidi and M. Chemek (2011). About Grafting of Single-Walled Carbon Nanotubes on the Oligo-NVinyl Carbazole and Copolymer Involving N-Vinylcarbazole and Hexylthiophene, Carbon Nanotubes - Polymer Nanocomposites, Dr. Siva Yellampalli (Ed.), ISBN: 978-953-307-498-6, InTech, Available from:

http://www.intechopen.com/books/carbon-nanotubes-polymer-nanocomposites/about-grafting-of-single-walledcarbon-nanotubes-on-the-oligo-n-vinyl-carbazole-and-copolymer-involv

\section{INTECH}

open science | open minds

\section{InTech Europe}

University Campus STeP Ri

Slavka Krautzeka 83/A

51000 Rijeka, Croatia

Phone: +385 (51) 770447

Fax: +385 (51) 686166

www.intechopen.com

\section{InTech China}

Unit 405, Office Block, Hotel Equatorial Shanghai

No.65, Yan An Road (West), Shanghai, 200040, China

中国上海市延安西路65号上海国际贵都大饭店办公楼 405 单元

Phone: +86-21-62489820

Fax: $+86-21-62489821$ 
(C) 2011 The Author(s). Licensee IntechOpen. This chapter is distributed under the terms of the Creative Commons Attribution-NonCommercialShareAlike-3.0 License, which permits use, distribution and reproduction for non-commercial purposes, provided the original is properly cited and derivative works building on this content are distributed under the same license. 